\title{
Donor-Type Nickel-Dithiolene Complexes Fused with Bulky Cycloalkane Substituents and Their Application in Molecular Conductors
}

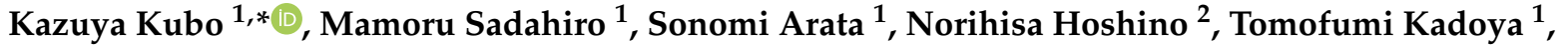 \\ Tomoyuki Akutagawa $^{2}$, Reizo Kato ${ }^{3} \mathbb{D}$ and Jun-ichi Yamada ${ }^{1}$ \\ 1 Graduate School of Science, University of Hyogo, 3-2-1, Kouto, Kamigori-cho, Akou-gun, \\ Kobe 678-1297, Japan; g1127sm@gmail.com (M.S.); rinrin520sono48@gmail.com (S.A.); \\ kadoya.t@sci.u-hyogo.ac.jp (T.K.); yamada@sci.u-hyogo.ac.jp (J.-i.Y.) \\ 2 Institute of Multidisciplinary Research for Advanced Materials, Tohoku University, 2-1-1 Katahira, \\ Aoba-ku, Sendai 980-8577, Japan; norihisa.hoshino.b5@tohoku.ac.jp (N.H.); akutagawa@tohoku.ac.jp (T.A.) \\ RIKEN, 2-1 Hirosawa, Wako-shi, Saitama 351-0023, Japan; reizo@riken.jp \\ * Correspondence: kubo@sci.u-hyogo.ac.jp; Tel.: +81-791-58-0163
}

check for updates

Citation: Kubo, K.; Sadahiro, M.; Arata, S.; Hoshino, N.; Kadoya, T.; Akutagawa, T.; Kato, R.; Yamada, J.-i. Donor-Type Nickel-Dithiolene Complexes Fused with Bulky Cycloalkane Substituents and Their Application in Molecular Conductors. Crystals 2021, 11, 1154. https:/ / doi.org/10.3390/cryst11101154

Academic Editor: Alberto Girlando

Received: 26 August 2021

Accepted: 14 September 2021

Published: 23 September 2021

Publisher's Note: MDPI stays neutral with regard to jurisdictional claims in published maps and institutional affiliations.

Copyright: (c) 2021 by the authors. Licensee MDPI, Basel, Switzerland. This article is an open access article distributed under the terms and conditions of the Creative Commons Attribution (CC BY) license (https:/ / creativecommons.org/licenses/by/ $4.0 /)$.

\begin{abstract}
The effects of substituents on the arrangement of metal-dithiolene complexes based on $\pi$-conjugated systems, which are extensively used to synthesize various functional materials, have not been studied adequately. New donor-type nickel-dithiolene complexes fused with bulky cycloalkane substituents [ $\left.\mathrm{Ni}\left(\mathrm{C}_{\mathrm{n}} \text {-dddt }\right)_{2}\right]\left(\mathrm{C}_{5}\right.$-dddt $=4 \mathrm{a}, 5,6,6 \mathrm{a}$-pentahydro-1,4-benzodithiin-2,3-dithiolate; $\mathrm{C}_{6}$ $\mathrm{dddt}=4 \mathrm{a}, 5,6,7,8,8 \mathrm{a}$-hexahydro-1,4-benzodithiin-2,3-dithiolate; $\mathrm{C}_{7}$-dddt $=4 \mathrm{a}, 5,6,7,8,9,9 \mathrm{a}$-heptahydro1,4-benzodithiin-2,3-dithiolate; and $\mathrm{C}_{8}$-dddt $=4 \mathrm{a}, 5,6,7,8,9,10,10 \mathrm{a}$-octahydro-1,4-benzodithiin-2,3dithiolate) were synthesized in this study. All the complexes were crystallized in cis-[Ni(cis- $\mathrm{C}_{n}$ $\mathrm{dddt})_{2}$ ] conformations with cis-oriented $(R, S)$ conformations around the cycloalkylene groups in the neutral state. Unique molecular arrangements with a three-dimensional network, a one-dimensional column, and a helical molecular arrangement were formed in the crystals owing to the flexible cycloalkane moieties. New 2:1 cation radical crystals of $\left[\mathrm{Ni}\left(\mathrm{C}_{5}-\mathrm{dddt}\right)_{2}\right]_{2}(\mathrm{X})\left(\mathrm{X}=\mathrm{ClO}_{4}{ }^{-}\right.$or $\left.\mathrm{PF}_{6}{ }^{-}\right)$, obtained by electrochemical crystallization, exhibited semiconducting behaviors $\left(\rho_{\mathrm{rt}}=0.8 \Omega \mathrm{cm}\right.$, $E_{\mathrm{a}}=0.09 \mathrm{eV}$ for the $\mathrm{ClO}_{4}{ }^{-}$crystal; $4.0 \Omega \mathrm{cm}, 0.13 \mathrm{eV}$ for the $\mathrm{PF}_{6}{ }^{-}$crystal) under ambient pressure due to spin-singlet states between the dimers of the donor, which were in accordance with the conducting behaviors under hydrostatic pressure $\left(\rho_{\mathrm{rt}}=0.2 \Omega \mathrm{cm}, E_{\mathrm{a}}=0.07 \mathrm{eV}\right.$ for the $\mathrm{ClO}_{4}{ }^{-}$crystal; $1.0 \Omega \mathrm{cm}$, $0.12 \mathrm{eV}$ for the $\mathrm{PF}_{6}{ }^{-}$crystal at $\left.2.0 \mathrm{GPa}\right)$.
\end{abstract}

Keywords: nickel-dithiolene complex; cycloalkane substituent; molecular conductor

\section{Introduction}

Organic $\pi$-conjugated molecules, including tetrathiafulvalene (TTF) skeletons, are among the most common building blocks for the realization of various functional materials [1]. The TTF molecule has an electron donor ability, which can help realize various charge transfers and produce radical cation crystals. The TTF-TCNQ (TCNQ: 7,7,8,8tetracyanoquinodimethane) is a prototype of charge-transfer compounds, where the highest occupied molecular orbital (HOMO) and lowest unoccupied molecular orbital (LUMO) bands of the open-shell donors and acceptors, respectively, contribute to the conduction [2,3]. It is the first organic conductor to exhibit a metallic conductivity within a wide temperature range with a minimum of $59 \mathrm{~K}$, where a sharp metal-to-insulator transition is observed [4]. Moreover, TTF has attracted significant research attention with the discovery of superconducting salts [5-8] based on TTF derivatives such as atetramethyltetraselenafulvalene (TMTSF) [9], bis(ethylenedithio)tetrathiafulvalene (BEDT-TTF) [10,11], and dimethyl(ethylenedithio)diselenadithiafulvalene (DMET) [12,13]. The conducting properties of molecular-based materials are significantly influenced by their molecular arrangements in 
crystal form. The cation radicals of BEDT-TTF and bis(ethylenedithio)tetraselenafulvalene (BETS) can crystallize in various donor packing motifs, including $\alpha-, \beta-, \theta-, \kappa_{-}$, and $\lambda$-type arrangements by combination with inorganic, organic, and organometallic anions [14-18]. Alternative strategies for tuning the molecular arrangements in organic conductors were reported based on organic synthesis techniques. A potential method involves the direct introduction of various substituents into the TTF or BEDT-TTF skeletons [19-42]. Kimura et al. reported that meso-2-(5,6-dihydro-1,3-dithiolo[4,5-b][1,4]dithiin-2-ylidene)5,6-dihydro-5,6-dimethyl-1,3-dithiolo[4,5-b][1,4]dithiin (meso-DMBEDT-TTF) forms a superconducting crystal $\beta$-(meso-DMBEDT-TTF $)_{2} \mathrm{PF}_{6}$ with a transition temperature at 4.3 $\mathrm{K}$ under a hydrostatic pressure of $4.0 \mathrm{kbar}$ due to a checkerboard-type charge order state on the donor molecules $[43,44]$. Another alternative method involves the introduction of bulky cycloalkane moieties into the donor molecules to determine the stacking of the donor molecules; thus, the ratio of the on-site Coulomb repulsion energy $U$ to the bandwidth $W$ can be controlled by changing $W$ for the organic Mott insulators based on the enhanced steric hindrance in the radical cation crystals of CnDT-EDO-TTF $(n=5,6$, 7, 8; cis-1,2-cycloalkylene-1,2-dithio)ethylenedioxytetrathiafulvalene] and its derivatives (Scheme 1) $[45,46]$.

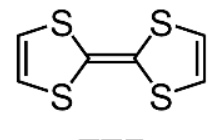

TTF<smiles>C1CSC2=C(S1)SC(=C1SC3=C(SCCS3)S1)S2</smiles>

BEDT-TTF<smiles>CC1=C(C)[Se]C(=C2SC3=C(SCCS3)S2)[Se]1</smiles>

DMET<smiles>CC(N)=c1ccc(=C(C)C(=N)N)cc1</smiles>

TCNQ<smiles>CC1=C(C)[Se]C(=C2[Se]C(C)=C(C)[Se]2)[Se]1</smiles>

TMTSF<smiles>CC1SC2=C(SC(=C3SC4=C(SCCS4)S3)S2)SC(C)C1C</smiles>
meso-DMBEDT-TTF<smiles>C1CCC2SC3=C(CCC2C1)SC(=C1SC2=C(OCCO2)S1)S3</smiles>

CnDT-EDO-TTF

Scheme 1. Organic components of molecular conductors.

Metal bis-dithiolene complexes can exhibit various oxidation states [47] and have smaller HOMO-LUMO gaps than those of the organic donors [48,49], which is advantageous for the components of molecular conductors. Electron-acceptor type [M(dmit $\left.)_{2}\right]$ $(\mathrm{M}=\mathrm{Pd}, \mathrm{Pt}$; dmit = 1,3-dithiole-2-thion-4,5-dithiolete) complexes with small gaps between the HOMO and LUMO form dimer structures. These structures induce crossing HOMOLUMO band inversions through metal-metal interactions in the solid state, which provide various conducting, magnetic, and other physical properties by combining with closed-shell cations [47,50-52]. The electron-donor-type metal bis-dithiolene complexes [M(dddt $\left.)_{2}\right]$ $(\mathrm{M}=\mathrm{Ni}, \mathrm{Pd}, \mathrm{Pt}$, and $\mathrm{Au}$; dddt = 5,6-dihydro-1,4-dithiine-2,3-ditholate $)$ are candidate materials for the development of molecular conductors due to their orbital symmetries, which are similar to those of BEDT-TTF [53-56]. A cation radical crystal, [Ni(dddt $\left.)_{2}\right]_{3}\left(\mathrm{AuBr}_{2}\right)_{2}$, is the first metal based on the donor-type metal-dithiolene complexes exhibiting metallic behavior down to at least $1.3 \mathrm{~K}$ [57]. Recently, Kato et al. reported a single-component molecular Dirac electron system based on $\mathrm{Pd}(\mathrm{dddt})_{2}$ that exhibits temperature-independent resistivity under high hydrostatic pressures [58-63]. The conducting and magnetic properties exhibited by the molecular crystals based on the dithiolene complexes are significantly dependent on the molecular arrangements of the metal-dithiolene complexes and organic molecular conductors. In the case of molecular conductors based on metal-dithiolene complexes, the molecular arrangements of the complexes are dependent on the combination of counter cations and anions in the crystals $[47,48]$. However, there are few reports on the substituent effects on the molecular arrangement, which influences the physical properties, despite the advantages of the components of molecular conductors [64,65]. Thus, we designed novel donor-type metal bis-dithiolene complexes $\left[\mathrm{Ni}\left(\mathrm{C}_{\mathrm{n}}-\mathrm{dddt}\right)_{2}\right]$ formed by a [Ni(dddt $)_{2}$ ] skeleton fused with bulky cycloalkane rings and investigated the substituent effects on the arrangement of the complexes and their physical properties (Scheme 2). 
Donor organic molecules fused with bulky substituents such as cycloalkane and dioxane moieties can form unique molecular arrangements in the crystals [66], which exhibit superconducting and metallic behaviors [45,46,67-69].<smiles>S=c1sc2c(s1)S[Ge]1(S2)Sc2sc(=S)sc2S1</smiles><smiles>C1CSC2=C(S1)S[Y]1(S2)SC2=C(SCCS2)S1</smiles>

$$
\left[\mathrm{M}(\mathrm{dmit})_{2}\right](\mathrm{M}=\mathrm{Ni}, \mathrm{Pd}, \mathrm{Pt})
$$$$
\left[\mathrm{M}(\mathrm{dddt})_{2}\right](\mathrm{M}=\mathrm{Ni}, \mathrm{Pd}, \mathrm{Pt}, \mathrm{Au})
$$

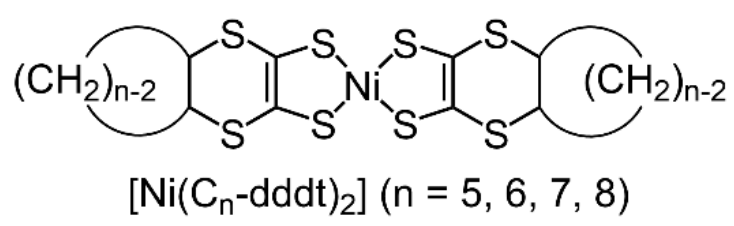

Scheme 2. Metal-dithiolene complexes as components of molecular conductors.

In this paper, we report the donor abilities of novel donor complexes $\left[\mathrm{Ni}\left(\mathrm{C}_{\mathrm{n}}-\mathrm{dddt}\right)_{2}\right]$ with two cycloalkane rings $\left(\mathrm{C}_{5}\right.$-dddt $=4 \mathrm{a}, 5,6,6 \mathrm{a}$-pentahydrro-1,4-benzodithiin-2,3-dithiolate; $\mathrm{C}_{6}$-dddt $=4 \mathrm{a}, 5,6,7,8,8 \mathrm{a}$-hexahydro-1,4-benzodithiin-2,3-dithiolate; $\mathrm{C}_{7}$-dddt $=4 \mathrm{a}, 5,6,7,8,9,9 \mathrm{a}$ heptahydro-1,4-benzodithiin-2,3-dithiolate, and $\mathrm{C}_{8}$-dddt $=4 \mathrm{a}, 5,6,7,8,9,10,10 \mathrm{a}$-octahydro1,4-benzodithiin-2,3-dithiolate) based on electrochemical measurements and electronic absorption spectra. The packing motifs of the neutral $\left[\mathrm{Ni}\left(\mathrm{C}_{\mathrm{n}}-\mathrm{dddt}\right)_{2}\right](n=5,6,7,8)$ were discussed based on $\mathrm{X}$-ray crystallographic analysis results. Furthermore, electronic features of new cation radical crystals $\left[\mathrm{Ni}\left(\mathrm{C}_{5}-\mathrm{dddt}\right)_{2}\right]_{2}[\mathrm{X}]\left(\mathrm{X}=\mathrm{ClO}_{4}{ }^{-}\right.$and $\left.\mathrm{PF}_{6}{ }^{-}\right)$were revealed using electrical resistivity, magnetic measurements, and band calculations based on the crystal structures.

\section{Materials and Methods}

\subsection{Materials}

All the solvents were of analytical grade and were used without further purification. All the reactions were performed in a nitrogen atmosphere. Oligo(1,3-dithiole-2,4,5trithione) $\left(\left(\mathrm{C}_{3} \mathrm{~S}_{5}\right)_{\mathrm{x}}\right)[70]$ and $\left(\mathrm{Bu}_{4} \mathrm{~N}\right)\left[\mathrm{Ni}(\mathrm{dddt})_{2}\right]$ [56] were prepared using a previously reported method.

\subsection{Synthesis}

2.2.1. Synthesis of 4,5-Cis(cyclopentalenedithio)-1,3-dithiole-2-thione (L1),

4,5-Cis(cyclohexylenedithio)-1,3-dithiole-2-thione (L2),

4,5-Cis(cycloheptalenedithio)-1,3-dithiole-2-thione (L3), and

4,5-Cis(cyclooctalenedithio)-1,3-dithiole-2-thione (L4)

In a nitrogen atmosphere, cyclopentene $(25 \mathrm{mmol})$ was dissolved in 1,2-dichloroethane $(25 \mathrm{~mL})$, and oligo(1,3-dithiole-2,4,5-trithione) $(10 \mathrm{mmol})$ was added. The resulting suspension was heated to $135^{\circ} \mathrm{C}$ for $14 \mathrm{~h}$ with stirring, and the reaction mixture was filtered to remove insoluble precipitates. The evaporation of the filtration in vacuo, followed by purification of the residue by column chromatography $\left(\mathrm{SiO}_{2}\right.$, carbon disulfide $\left(\mathrm{CS}_{2}\right)$-hexane 1:3), yielded 67.6\% 4,5-cis(cyclopentalenedithio)-1,3-dithiole-2-thione (L1) as yellow crystals after recrystallization from hot ethanol (EtOH). Moreover, 4,5-cis(cyclohexylenedithio)1,3-dithiole-2-thione (L2), 4,5-cis(cycloheptalenedithio)-1,3-dithiole-2-thione (L3), and 4,5cis(cyclooctalenedithio)-1,3-dithiole-2-thione (L4) were obtained using a similar procedure with corresponding cycloalkenes as starting materials, yielding $32.7 \% \mathbf{L 2}, 77.6 \% \mathbf{L 3}$, and $69.2 \%$ L4. 
2.2.2. Synthesis of 4,5-Cis(cyclopentalenedithio)-1,3-dithiole-2-one ( $\left.\mathbf{L 1}^{\prime}\right)$ and

4,5-Cis(cyclohexylenedithio)-1,3-dithiole-2-one ( $\left.\mathbf{L 2}^{\prime}\right)$,

4,5-Cis(cycloheptalenedithio)-1,3-dithiole-2-one $\left(\mathbf{L 3}^{\prime}\right)$, and

4,5-Cis(cyclooctalenedithio)-1,3-dithiole-2-one ( $\left.\mathbf{L 4}^{\prime} \mathbf{}^{\prime}\right)$

Mercuric acetate $(1.5 \mathrm{mmol})$ was added to a solution of $\mathbf{L 1}^{\prime}(1 \mathrm{mmol})$ in tetrahydrofuranacetic acid (2:1, $45 \mathrm{~mL})$, and the resulting white suspension was stirred for $30 \mathrm{~min}$ at $20^{\circ} \mathrm{C}$. The resulting white precipitate was removed by filtration using Celite and washed thoroughly using chloroform. The combined organic phases were washed using water $(2 \times 100 \mathrm{~mL})$, saturated sodium hydrogen carbonate $(2 \times 100 \mathrm{~mL})$, and water $(1 \times 100 \mathrm{~mL})$, and then they were dried using magnesium sulfate. The removal of the solvent in vacuo yielded 98\% 4,5-cis(cyclopentalenedithio)-1,3-dithiole-2-one ( $\left.\mathbf{L 1}^{\prime}\right)$ as large pale yellow needle crystals. Moreover, 4,5-cis(cyclohexylenedithio)-1,3-dithiole-2-one (L2'), 4,5-cis(cycloheptalenedithio)-1,3-dithiole-2-one ( $\mathbf{L 3}^{\prime}$ ), and 4,5-cis(cyclooctalenedithio)-1,3dithiole-2-one $\left(\mathbf{L 4}^{\prime}\right)$ were obtained using a similar procedure; thus yielding $97 \% \mathbf{L 2}^{\prime}, 98 \%$ $\mathbf{L 3}^{\prime}$, and $97 \% \mathbf{L} 4^{\prime}$.

2.2.3. Synthesis of Monoanionic Complexes $\left(\mathrm{Bu}_{4} \mathrm{~N}\right)\left[\mathrm{Ni}\left(\mathrm{C}_{\mathrm{n}}-\mathrm{dddt}\right)_{2}\right](n=5, \mathbf{1} ; n=6,2 ; n=7$, 3 ; and $n=8,4)$

Sodium $(3.0 \mathrm{mmol})$ and $\mathbf{L m}^{\prime}(\mathrm{m}=1-4)(1.2 \mathrm{mmol})$ were dissolved in EtOH $(15 \mathrm{~mL})$. The resulting clear orange solution was dropped into an $\mathrm{EtOH}$ solution $(15 \mathrm{~mL})$ of $\mathrm{NiCl}_{2} \cdot 6 \mathrm{H}_{2} \mathrm{O}$ $(0.6 \mathrm{mmol})$ for $30 \mathrm{~min}$ with stirring. The resulting solution had a dark purple color. It was stirred in the air for a further $30 \mathrm{~min}$, and the color changed to dark green as the reaction proceeded. After filtration to remove insoluble precipitates, one equivalent tetrabutylammonium bromide was added to the solution, and a dark green solid precipitated immediately. The green solids of monoanionic complexes 1-4 were collected by filtration and recrystallized using acetone. The yields for $1,2,3$, and 4 were $79.6 \%, 63.0 \%, 46.4 \%$, and $38.8 \%$, respectively.

2.2.4. Synthesis of Neutral Complexes $\left[\mathrm{Ni}\left(\mathrm{C}_{\mathrm{n}} \text {-dddt }\right)_{2}\right](n=5,5 ; n=6,6 ; n=7,7$; and $n=8,8)$

An acetonitrile $\left(\mathrm{CH}_{3} \mathrm{CN}\right)(50 \mathrm{~mL})$ solution of iodine $(1.3 \mathrm{mmol})$ was added to a $\mathrm{CH}_{3} \mathrm{CN}$ solution (100 mL) of monoanionic complexes 1-4 (0.23 mmol). Black precipitates of 5-8 were obtained immediately. The precipitates of the neutral complexes were collected by filtration, washed using $\mathrm{CH}_{3} \mathrm{CN}$ and methanol, and dried under reduced pressure. Black block-shaped single crystals of the neutral complexes 5-8, which were suitable for X-ray crystallographic analyses, were obtained by recrystallization from their carbon disulfide solutions. The yields for $5,6,7$, and 8 were $69.2 \%, 31.5 \%, 62.9 \%$, and $36.8 \%$, respectively. The elemental analysis results for these complexes are summarized in Table 1.

Table 1. Results of the elemental analyses of 1-8.

\begin{tabular}{|c|c|c|c|c|c|c|c|c|}
\hline \multirow{2}{*}{$\begin{array}{l}\text { Complex } \\
\text { Formula }\end{array}$} & \multicolumn{3}{|c|}{ Observed (Calculation Result) (\%) } & \multirow{2}{*}{$\begin{array}{l}\text { Complex } \\
\text { Formula }\end{array}$} & \multicolumn{4}{|c|}{ Observed (Calculation Result) (\%) } \\
\hline & $\mathrm{C}$ & $\mathbf{H}$ & $\mathbf{N}$ & & $\mathrm{C}$ & $\mathbf{H}$ & $\mathrm{Ni}$ & $S$ \\
\hline $\begin{array}{c}\mathbf{1} \\
\mathrm{C}_{30} \mathrm{H}_{52} \mathrm{NNiS}_{8}\end{array}$ & $\begin{array}{c}48.32 \\
(48.56)\end{array}$ & $\begin{array}{c}6.91 \\
(7.06)\end{array}$ & $\begin{array}{c}1.89 \\
(1.89)\end{array}$ & $\frac{5}{\mathrm{C}_{14} \mathrm{H}_{16} \mathrm{NiS}_{8}}$ & $\begin{array}{c}33.59 \\
(33.66)\end{array}$ & $\begin{array}{c}3.14 \\
(3.23)\end{array}$ & $\begin{array}{c}11.58 \\
(11.75)\end{array}$ & $\begin{array}{l}51.33 \\
(51.36)\end{array}$ \\
\hline $\begin{array}{c}2 \\
\mathrm{C}_{32} \mathrm{H}_{56} \mathrm{NNiS}_{8}\end{array}$ & $\begin{array}{c}49.65 \\
(49.91)\end{array}$ & $\begin{array}{c}7.26 \\
(7.33)\end{array}$ & $\begin{array}{c}1.85 \\
(1.82)\end{array}$ & $\stackrel{6}{\mathrm{C}_{16} \mathrm{H}_{20} \mathrm{NiS}_{8}}$ & $\begin{array}{c}36.21 \\
(36.43)\end{array}$ & $\begin{array}{c}3.70 \\
(3.82)\end{array}$ & $\begin{array}{c}11.08 \\
(11.13)\end{array}$ & $\begin{array}{c}48.60 \\
(48.63)\end{array}$ \\
\hline $\begin{array}{c}3 \\
\mathrm{C}_{34} \mathrm{H}_{60} \mathrm{NNiS}_{8}\end{array}$ & $\begin{array}{l}50.88 \\
(51.17)\end{array}$ & $\begin{array}{c}7.50 \\
(7.58)\end{array}$ & $\begin{array}{c}1.67 \\
(1.76)\end{array}$ & $\begin{array}{c}7 \\
\mathrm{C}_{18} \mathrm{H}_{24} \mathrm{NiS}_{8}\end{array}$ & $\begin{array}{c}38.87 \\
(38.91)\end{array}$ & $\begin{array}{c}4.26 \\
(4.35)\end{array}$ & $\begin{array}{c}10.44 \\
(10.56)\end{array}$ & $\begin{array}{c}46.40 \\
(46.17)\end{array}$ \\
\hline $\begin{array}{c}\mathbf{4} \\
\mathrm{C}_{36} \mathrm{H}_{64} \mathrm{NNiS}_{8}\end{array}$ & $\begin{array}{l}51.90 \\
(52.34)\end{array}$ & $\begin{array}{c}7.71 \\
(7.81)\end{array}$ & $\begin{array}{c}1.70 \\
(1.70)\end{array}$ & $\begin{array}{c}\mathbf{8} \\
\mathrm{C}_{20} \mathrm{H}_{28} \mathrm{NiS}_{8}\end{array}$ & $\begin{array}{c}41.00 \\
(41.16)\end{array}$ & $\begin{array}{c}4.81 \\
(4.84)\end{array}$ & $\begin{array}{c}9.81 \\
(10.06)\end{array}$ & $\begin{array}{c}43.86 \\
(43.95)\end{array}$ \\
\hline
\end{tabular}


2.2.5. Synthesis of Radical Cation Crystals $\left[\mathrm{Ni}\left(\mathrm{C}_{5}-\mathrm{dddt}\right)_{2}\right]_{2}\left[\mathrm{ClO}_{4}\right](9)$ and $\left[\mathrm{Ni}\left(\mathrm{C}_{5} \text {-dddt }\right)_{2}\right]_{2}\left[\mathrm{PF}_{6}\right](\mathbf{1 0})$

Dichloromethane $\left(\mathrm{CH}_{2} \mathrm{Cl}_{2}\right)$ solutions $(10 \mathrm{~mL})$ of $5(0.03 \mathrm{mmol})$ containing $\left(\mathrm{Bu}_{4} \mathrm{~N}\right)(\mathrm{X})$ $\left(\mathrm{X}=\mathrm{ClO}_{4}\right.$ or $\left.\mathrm{PF}_{6}\right)(0.09 \mathrm{mmol})$ as electrolytes were electrolyzed under constant-current conditions $(3 \mu \mathrm{A})$ for three days in an $\mathrm{H}$-shaped cell equipped with platinum wire electrodes in an argon atmosphere at $20^{\circ} \mathrm{C}$. Black crystals of $\mathbf{9}$ and $\mathbf{1 0}$ were formed on the anode surface. The chemical formulas of $\mathbf{9}$ and $\mathbf{1 0}$ were confirmed by X-ray crystal structural analyses.

\subsection{Physical Measurements}

\subsubsection{Elemental Analyses}

The analyses of the carbon, hydrogen, and nitrogen elements were performed using a PERKIN-ELMER 240 C elemental analyzer for 1, 3, 7; and a Yanako MT-6 CHN CORDER for $2,4,5,6$, and 8 . The elemental analyses of the nickel and sulfur atoms of the neutral complexes 5-8 were performed using a SHIMADZU ICPS-1000IV by the Chemical Analysis Team of AD\&SD in RIKEN.

\subsubsection{Electrochemical Measurements}

Cyclic voltammograms of monoanionic complexes 1-4 were obtained using acetonitrile solutions $\left(1 \times 10^{-3} \mathrm{~mol} \mathrm{~L}^{-1}\right)$ with $\left(\mathrm{Bu}_{4} \mathrm{~N}\right)\left(\mathrm{ClO}_{4}\right)(0.1 \mathrm{M})$ as a supporting electrolyte and recorded using a BAS ALS/[H] CH Instruments Model 610 electrochemical analyzer combined with an $\mathrm{Ag} / \mathrm{Ag}^{+}$reference electrode, platinum counter electrode, and glassy carbon working electrode at room temperature. The scan rate of the measurements was $100 \mathrm{mV} / \mathrm{s}$.

\subsubsection{Electronic Absorption Spectra}

The electronic absorption spectra (300-1600 nm) of 1-8 in $\mathrm{CH}_{2} \mathrm{Cl}_{2}, \mathrm{CH}_{3} \mathrm{CN}$, and benzene solutions $\left(5 \times 10^{-5} \mathrm{~mol} \mathrm{~L}^{-1}\right)$ at room temperature were measured by the Chemical Analysis Team of AD\&SD in RIKEN using a Shimadzu UV-3100 system.

\subsubsection{Electrical Resistivity}

The temperature dependence of the electrical resistivity was measured using the standard four-probe method at ambient pressure for 9 and 10. Gold wires $(15 \mu \mathrm{m}$ in diameter) were attached to the crystal with a carbon paste. Resistivity measurements under the hydrostatic pressure of the salt were performed within the range from $0.3-1.8 \mathrm{GPa}$ using a clamp-type piston-cylinder high-pressure cell [71,72].

\subsubsection{Magnetic Susceptibility}

The magnetic susceptibilities of $\mathbf{9}(15 \mathrm{mg})$ and $\mathbf{1 0}(20 \mathrm{mg})$ were measured in a magnetic field of $1 \mathrm{~T}$ using a superconducting quantum interference device (SQUID) magnetometer (Quantum Design, MPMS-XL7) within the temperature range of 2-300 K.

\subsubsection{Band Calculation}

The intermolecular overlap integrals $(S)$ between the frontier orbitals were calculated based on the extended Hückel molecular orbital (MO) method. The semi-empirical parameters for the Slater-type atomic orbitals were obtained from the literature [73-75].

\subsubsection{Crystal Structure Determinations of L2-L4, Neutral Complexes 5-8, and Radical} Cation Crystals $\mathbf{9}$ and $\mathbf{1 0}$

Crystallographic data for the single crystals of $\mathbf{L 2}-\mathbf{L} 4, \mathbf{5 - 8}$, and $\mathbf{9 - 1 0}$ were obtained using a Rigaku MicroMax-007 diffractometer with a multilayer mirror monochromated Mo-K $\alpha(\lambda=0.71073 \AA)$ and charge-coupled device detector at $93 \mathrm{~K}$. Structural refinements were carried out using the full-matrix least-squares method on $F^{2}$ [76]. The structures were determined and refined using SHELXL-2018 in the Olex2 software package [77,78]. The parameters were refined using anisotropic temperature factors, with the exception 
of the hydrogen atoms, which were parametrically refined using the riding model with a fixed C-H bond distance of $0.95 \AA$. The crystallographic data for $\mathbf{L 2}-\mathbf{L} \mathbf{4}, \mathbf{5 - 8}$, and $\mathbf{9 - 1 0}$ are summarized in Tables $2-4$, respectively.

Table 2. Crystallographic data for neutral complexes L2-L4.

\begin{tabular}{|c|c|c|c|}
\hline & L2 & L3 & L4 \\
\hline Chemical formula & $\mathrm{C}_{7.2} \mathrm{H}_{8} \mathrm{~S}_{4}$ & $\mathrm{C}_{8} \mathrm{H}_{9.60} \mathrm{~S}_{4}$ & $\mathrm{C}_{7.34} \mathrm{H}_{9.34} \mathrm{~S}_{3.34}$ \\
\hline Crystal size $/ \mathrm{mm}^{3}$ & $0.40 \times 0.10 \times 0.04$ & $0.30 \times 0.06 \times 0.03$ & $0.40 \times 0.03 \times 0.02$ \\
\hline Formula weight & 222.78 & 234.00 & 204.45 \\
\hline Crystal system & Monoclinic & Monoclinic & Monoclinic \\
\hline Space group & $P 2_{1} / \mathrm{c}$ & $P 2_{1} / \mathrm{c}$ & $P 2 / \mathrm{c}$ \\
\hline$a / \AA$ & $12.7079(3)$ & $5.3224(3)$ & $11.2835(7)$ \\
\hline$b / \AA$ & $9.8356(2)$ & $21.7855(10)$ & $6.8878(3)$ \\
\hline$c / \AA$ & $18.7846(4)$ & $10.5687(5)$ & $17.1727(13)$ \\
\hline$\alpha /{ }^{\circ}$ & 90 & 90 & 90 \\
\hline$\beta /{ }^{\circ}$ & $105.640(2)$ & $95.793(5)$ & $106.533(7)$ \\
\hline$\gamma /{ }^{\circ}$ & 90 & 90 & 90 \\
\hline$V / \AA^{3}$ & $2260.95(9)$ & $1219.19(11)$ & $1279.46(14)$ \\
\hline Z & 10 & 5 & 6 \\
\hline$T / K$ & 93 & 93 & 93 \\
\hline$\mu(\mathrm{Mo} \mathrm{K} \alpha) / \mathrm{mm}^{-1}$ & 0.980 & 0.913 & 0.874 \\
\hline$D_{\text {calc }} / \mathrm{g} \mathrm{cm}^{-3}$ & 1.636 & 1.594 & 1.592 \\
\hline$F(000)$ & 1152 & 608 & 640 \\
\hline$\lambda(\mathrm{Mo}-\mathrm{K} \alpha) / \AA$ & 0.71073 & 0.71073 & 0.71073 \\
\hline Measured $2 \theta$ range ${ }^{\circ}$ & $4.75-60.98$ & $3.938-60.722$ & $3.766-60.41$ \\
\hline $\begin{array}{l}\text { No. of reflections } \\
\text { collected }\end{array}$ & 22,206 & 10,849 & 11,351 \\
\hline $\begin{array}{l}\text { Independent } \\
\text { reflections }\end{array}$ & 16,862 & 7823 & 6705 \\
\hline $\begin{array}{l}\text { Observed reflections } \\
\text { with } I>2.00 \sigma(I)\end{array}$ & 5456 & 2882 & 2973 \\
\hline$R_{\text {int }}$ & 0.0191 & 0.0291 & 0.0255 \\
\hline$R\left(F^{2}\right)(I>2.00 \sigma(I))^{\mathrm{a}}$ & 0.0211 & 0.0293 & 0.0267 \\
\hline$w R\left(F^{2}\right)(\text { all data })^{b}$ & 0.0537 & 0.0740 & 0.0654 \\
\hline Goodness of fit (GOF) & 1.064 & 1.056 & 1.041 \\
\hline CCDC number & $2,103,657$ & $2,103,658$ & $2,103,659$ \\
\hline
\end{tabular}

Table 3. Crystallographic data for neutral complexes 5-8.

\begin{tabular}{|c|c|c|c|c|}
\hline & 5 & 6 & 7 & 8 \\
\hline Chemical formula & $\mathrm{C}_{14} \mathrm{H}_{16} \mathrm{NiS}_{8}$ & $\mathrm{C}_{16} \mathrm{H}_{20} \mathrm{NiS}_{8}$ & $\mathrm{C}_{7.2} \mathrm{H}_{9.6} \mathrm{Ni}_{0.4} \mathrm{~S}_{3.2}$ & $\mathrm{C}_{6.67} \mathrm{H}_{9.32} \mathrm{Ni}_{0.33} \mathrm{~S}_{2.66}$ \\
\hline Crystal size $/ \mathrm{mm}^{3}$ & $0.14 \times 0.11 \times 0.06$ & $0.16 \times 0.09 \times 0.06$ & $0.07 \times 0.04 \times 0.01$ & $0.18 \times 0.07 \times 0.07$ \\
\hline Formula weight & 499.46 & 527.51 & 222.22 & 194.41 \\
\hline Crystal system & Monoclinic & Monoclinic & Monoclinic & Triclinic \\
\hline Space group & $P 2_{1} / \mathrm{n}$ & $P 2_{1}$ & $P 2_{1} / \mathrm{n}$ & $P-1$ \\
\hline$a / \AA$ & $6.2830(2)$ & $8.0303(3)$ & $12.5305(6)$ & $6.8973(10)$ \\
\hline$b / \AA$ & $9.8825(3)$ & $8.8084(4)$ & $6.7500(3)$ & $8.6190(13)$ \\
\hline$c / \AA$ & $15.2978(4)$ & $14.8128(5)$ & $13.6312(6)$ & $11.5730(15)$ \\
\hline$\alpha /{ }^{\circ}$ & 90 & 90 & 90 & $69.507(13)$ \\
\hline$\beta /{ }^{\circ}$ & $100.685(3)$ & $105.033(4)$ & 108.057(5) & $85.237(11)$ \\
\hline$\gamma /{ }^{\circ}$ & 90 & 90 & 90 & $71.298(13)$ \\
\hline$V / \AA^{3}$ & $933.40(5)$ & 1011.91(7) & 1096.15(9) & $610.09(16)$ \\
\hline$Z$ & 2 & 2 & 5 & 3 \\
\hline $\mathrm{T} / \mathrm{K}$ & 93 & 93 & 93 & 93 \\
\hline$\mu(\mathrm{Mo} \mathrm{K} \alpha) / \mathrm{mm}^{-1}$ & 1.928 & 1.783 & 1.651 & 1.486 \\
\hline$D_{\text {calc }} / \mathrm{g} \mathrm{cm}^{-3}$ & 1.777 & 1.731 & 1.683 & 1.587 \\
\hline
\end{tabular}


Table 3. Cont.

\begin{tabular}{|c|c|c|c|c|}
\hline & 5 & 6 & 7 & 8 \\
\hline$F(000)$ & 512 & 544 & 576 & 304 \\
\hline$\lambda(\mathrm{Mo}-\mathrm{K} \alpha) / \AA$ & 0.71073 & 0.71073 & 0.71073 & 0.71073 \\
\hline Measured $2 \theta$ range $^{\circ}$ & $4.938-60.77$ & $5.224-60.742$ & $5.376-61.08$ & $3.75-60.606$ \\
\hline $\begin{array}{l}\text { No. of reflections } \\
\text { collected }\end{array}$ & 10,661 & 9330 & 9850 & 9364 \\
\hline Independent reflections & 7606 & 6979 & 6434 & 3699 \\
\hline $\begin{array}{l}\text { Observed reflections } \\
\text { with } I>2.00 \sigma(I)\end{array}$ & 2215 & 4857 & 2436 & 2568 \\
\hline$R_{\text {int }}$ & 0.0182 & 0.0187 & 0.0226 & 0.0267 \\
\hline$R\left(F^{2}\right)(I>2.00 \sigma(I))^{\mathrm{a}}$ & 0.0237 & 0.0499 & 0.0252 & 0.0827 \\
\hline$w R\left(F^{2}\right)$ (all data) ${ }^{\mathrm{b}}$ & 0.0595 & 0.1305 & 0.0544 & 0.1977 \\
\hline GOF & 1.056 & 1.215 & 1.051 & 1.185 \\
\hline Flack parameter & & $0.328(7)$ & & \\
\hline CCDC number & $2,103,660$ & $2,103,661$ & $2,103,662$ & $2,103,663$ \\
\hline
\end{tabular}

${ }^{\mathrm{a}} R\left(F^{2}\right)=\Sigma\left(F_{\mathrm{o}}{ }^{2}-{F_{\mathrm{c}}}^{2}\right) / \Sigma{F_{\mathrm{o}}}^{2}{ }^{\mathrm{b}} w R\left(F^{2}\right)=\left[\Sigma w\left(F_{\mathrm{o}}{ }^{2}-F_{\mathrm{c}}{ }^{2}\right)^{2} / \Sigma w\left(F_{\mathrm{o}}{ }^{2}\right)^{2}\right]^{1 / 2}$ and $w^{-1}=\left[\Sigma^{2}\left(F^{2}\right)+(0.0341 P)^{2}+0.4506 P\right]$ for 5; $w^{-1}=\left[\Sigma^{2}\left(F^{2}\right)+\right.$ $\left.(0.0110 P)^{2}+9.3099 P\right]$ for $6 ; w^{-1}=\left[\Sigma^{2}\left(F^{2}\right)+(0.0275 P)^{2}+0.2769 P\right]$ for 7 ; and $w^{-1}=\left[\Sigma^{2}\left(F^{2}\right)+(0.0195 P)^{2}+10.6333 P\right]$ for $8\left(\right.$ where $P=\left(F_{\mathrm{o}}^{2}+\right.$ $\left.2 F_{\mathrm{c}}^{2}\right) / 3$ ).

Table 4. Crystallographic data for the radical cation crystals 9 and $\mathbf{1 0 .}$

\begin{tabular}{|c|c|c|}
\hline & 9 & 10 \\
\hline Chemical formula & $\mathrm{C}_{7} \mathrm{H}_{8} \mathrm{Cl}_{0.25} \mathrm{Ni}_{0.50} \mathrm{OS}_{4}$ & $\mathrm{C}_{7} \mathrm{H}_{8} \mathrm{~F}_{1.5} \mathrm{Ni}_{0.5} \mathrm{P}_{0.25} \mathrm{~S}_{4}$ \\
\hline Crystal size $/ \mathrm{mm}^{3}$ & $0.12 \times 0.12 \times 0.08$ & $0.14 \times 0.07 \times 0.01$ \\
\hline Formula weight & 274.59 & 285.97 \\
\hline Crystal system & Monoclinic & Monoclinic \\
\hline Space group & $P 2 / \mathrm{c}$ & $P 2 / \mathrm{c}$ \\
\hline$a / \AA$ & $12.6888(3)$ & $12.6865(4)$ \\
\hline$b / \AA$ & $6.25150(10)$ & $6.3020(2)$ \\
\hline$c / \AA$ & $24.1229(6)$ & $24.3145(8)$ \\
\hline$\alpha /{ }^{\circ}$ & 90 & 90 \\
\hline$\beta /{ }^{\circ}$ & $93.462(2)$ & $92.900(3)$ \\
\hline$\gamma /{ }^{\circ}$ & 90 & 90 \\
\hline$V / \AA^{3}$ & 1910.03(7) & 1941.46(11) \\
\hline Z & 8 & 8 \\
\hline$T / K$ & 93 & 93 \\
\hline$\mu(\mathrm{Mo} \mathrm{K} \alpha) / \mathrm{mm}^{-1}$ & 1.969 & 1.928 \\
\hline$D_{\text {calc }} / \mathrm{g} \mathrm{cm}^{-3}$ & 1.910 & 1.957 \\
\hline$F(000)$ & 1122 & 1162 \\
\hline$\lambda(\mathrm{Mo}-\mathrm{K} \alpha) / \AA$ & 0.71073 & 0.71073 \\
\hline Measured $2 \theta$ range $^{\circ}$ & $4.782-60.788$ & $4.518-60.73$ \\
\hline No. of reflections collected & 16,993 & 17,389 \\
\hline Independent reflections & 12,771 & 9840 \\
\hline $\begin{array}{l}\text { Observed reflections with } I> \\
2.00 \sigma(I)\end{array}$ & 4756 & 4142 \\
\hline$R_{\text {int }}$ & 0.0135 & 0.0338 \\
\hline$R\left(F^{2}\right)(I>2.00 \sigma(I))^{\mathrm{a}}$ & 0.0302 & 0.0335 \\
\hline$w R\left(F^{2}\right)(\text { all data })^{\mathrm{b}}$ & 0.0659 & 0.0737 \\
\hline GOF & 1.068 & 1.024 \\
\hline CCDC number & $2,103,664$ & $2,103,665$ \\
\hline
\end{tabular}




\section{Results and Discussion}

\subsection{Synthesis of Complexes $\mathbf{1 - 8}$}

\subsubsection{Syntheses and Molecular Structures of Precursors L1-L4}

One of the most effective methods for synthesizing various TTF derivatives and their precursors involves $[2+4]$ cycloadditions of $\left(\mathrm{C}_{3} \mathrm{~S}_{5}\right)_{\mathrm{X}}($ as $4 \pi)$ and a molecule that involves one of its external double bonds (as $2 \pi$ ) [79]. This reaction is stereospecific, similar to the $[2+4]$ cycloaddition of tetrathiooxalate with alkanes, thus providing a cis-oriented compound [80]. Precursors L1-L4 were synthesized using a modified version of a method outlined in a previous study, by the [2+4] cycloadditions of $\left(\mathrm{C}_{3} \mathrm{~S}_{5}\right)_{\mathrm{x}}$ and cycloheptene, cyclohexene, cycloheptene, and cyclooctene [81]. The cycloalkylene residues were cisoriented with respect to the newly formed 1,4-dithiene rings. Single crystals of L1-L4 were obtained by recrystallization from their dichloromethane solutions, which were suitable for X-ray crystallographic analyses, with the exception of L1. Figure 1 presents the molecular structures of two crystallographically independent molecules A and B in the crystal of L2. The fused cyclohexane moieties in molecules A and B formed cis-oriented $(R, S)$ conformations at the two carbons $C(4)-C(5)$ and $C(13)-C(14)$, respectively. Stable chair-type configurations of the cyclohexylene groups were observed for molecules $\mathrm{A}$ and B. A similar cis-oriented conformation was observed in the crystals of 4,5-(1,4-dioxanediyl2,3-dithio)-1,3-dithiole-2-thione and 4,5-(cis-cyclohexylenedithio)-1,3-dithiole-2-one [82,83]. The bond distances of $\mathrm{C}=\mathrm{C}$ and $\mathrm{C}=\mathrm{S}$ were $1.349 \AA$ and $1.648 \AA$ for molecule $\mathrm{A}$, and $1.352 \AA$ and $1.648 \AA$ for molecule B. The angles between the planes formed by $\mathrm{S}(1)-\mathrm{C}(2)-\mathrm{C}(3)-\mathrm{S}(2)$ and $S(3)-C(2)-C(3)-S(4)$ in molecule $A$ and $S(6)-C(11)-C(12)-S(7)$ and $S(8)-C(11)-C(12)-S(9)$ in molecule $\mathrm{B}$ were $3.86^{\circ}$ and $3.08^{\circ}$, respectively. The bond distances and angles indicate that the $\mathrm{C}_{3} \mathrm{~S}_{5}$ moieties of molecules $\mathrm{A}$ and $\mathrm{B}$ formed similar planar structures. The torsion angles around the fused cyclohexyl group in molecule $A$ were $-71.20^{\circ},-6.76^{\circ}$, and $56.18^{\circ}$ for $C(2)$ $S(1)-C(4)-C(5), C(3)-S(2)-C(5)-C(4)$, and $S(1)-C(4)-C(5)-S(2)$, respectively. The corresponding torsion angles in molecule B were $-62.56^{\circ},-26.37^{\circ}$, and $63.91^{\circ}$ for $C(11)-S(6)-C(13)-C(14)$, $\mathrm{C}(12)-\mathrm{S}(7)-\mathrm{C}(14)-\mathrm{C}(13)$, and $\mathrm{S}(6)-\mathrm{C}(13)-\mathrm{C}(14)-\mathrm{S}(7)$, respectively. The comparison of the torsion angles between molecules $\mathrm{A}$ and $\mathrm{B}$ revealed that the fused cyclohexylene group in molecule A deviated more from the $\mathrm{C}_{3} \mathrm{~S}_{5}$ plane at the $\mathrm{S}(1)$ and $\mathrm{S}(2)$ positions than that of molecule B.

(a)
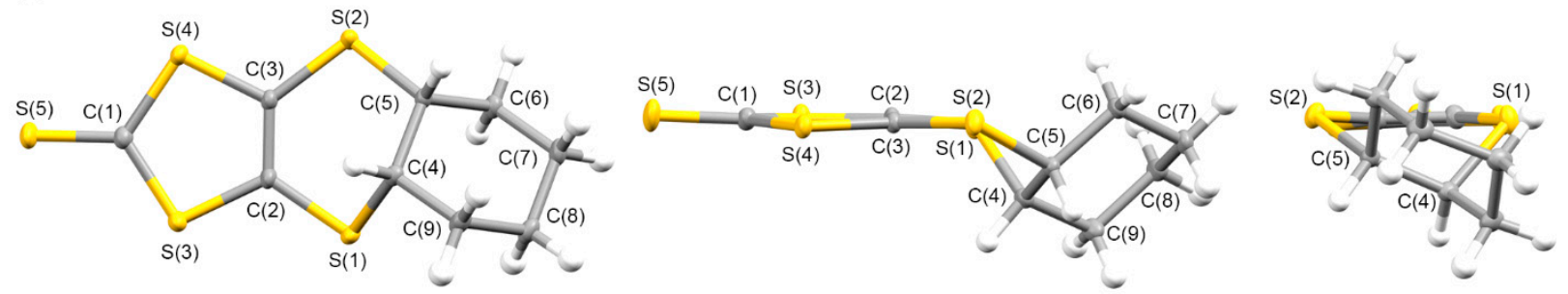

(b)
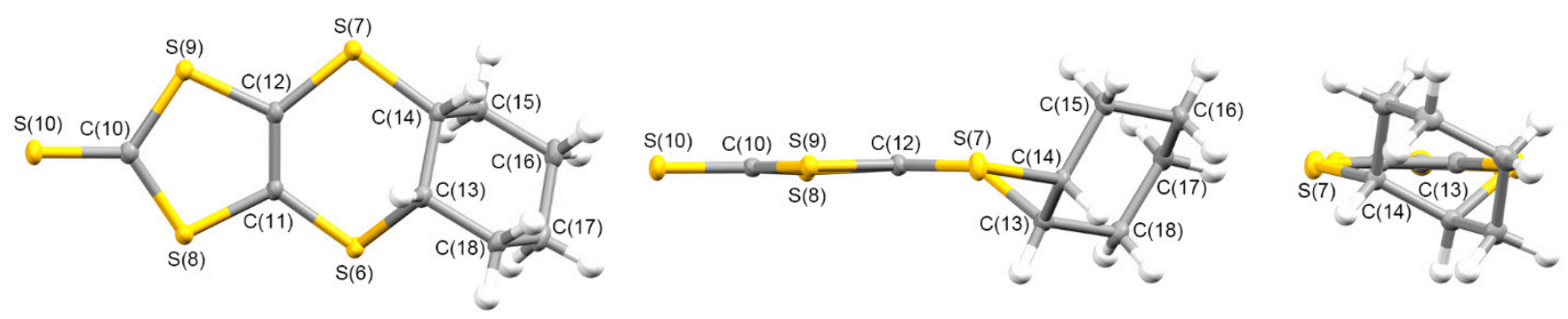

Figure 1. Molecular structures of two crystallographically independent molecules, (a) A and (b) B, in the crystal of $\mathbf{L} 2$ along the vertical, parallel, and end-on directions on the $\mathrm{C}_{3} \mathrm{~S}_{5}$ molecular plane with atom labels.

Figure 2 presents the molecular structures of $\mathbf{L} 3$ and $\mathbf{L} 4$. The fused cycloheptane 
and cyclooctane moieties formed cis-oriented $(R, S)$ conformations at the two carbons $C(4)$ and $C(5)$, respectively, in addition to molecule L2. Twist-chair- and boat-chair-type configurations of the cycloheptylene and cyclooctylene groups were formed in L3 and L4, which were observed in the crystals of CnDT-EDO-TTF $(n=7,8)[45]$. The $\mathrm{C}_{3} \mathrm{~S}_{5}$ moieties of L3 and L4 were planar structures, as observed in the crystal of $\mathbf{L} 2$; where the bond lengths $C(1)=S(5)$ and $C(2)=C(3)$ and the angles between the planes formed by $S(1)-C(2)-C(3)-S(2)$ and $S(3)-C(2)-C(3)-S(4)$ were $1.656 \AA, 1.355 \AA$, and $2.89^{\circ}$ for L3; and $1.647 \AA, 1.344 \AA$, and $2.75^{\circ}$ for $\mathbf{L} 4$, respectively. The torsion angles around the fused cycloalkylene groups of $\mathrm{C}(2)-\mathrm{S}(1)-\mathrm{C}(4)-\mathrm{C}(5), \mathrm{C}(3)-\mathrm{S}(2)-\mathrm{C}(5)-\mathrm{C}(4)$, and $\mathrm{S}(1)-\mathrm{C}(4)-\mathrm{C}(5)-\mathrm{S}(2)$ were $57.68^{\circ}, 42.60^{\circ}$, and $-72.47^{\circ}$ for $\mathbf{L} 3$; and $58.00^{\circ}, 41.11^{\circ}$, and $-72.18^{\circ}$ for $\mathbf{L} 4$, respectively.

(a)
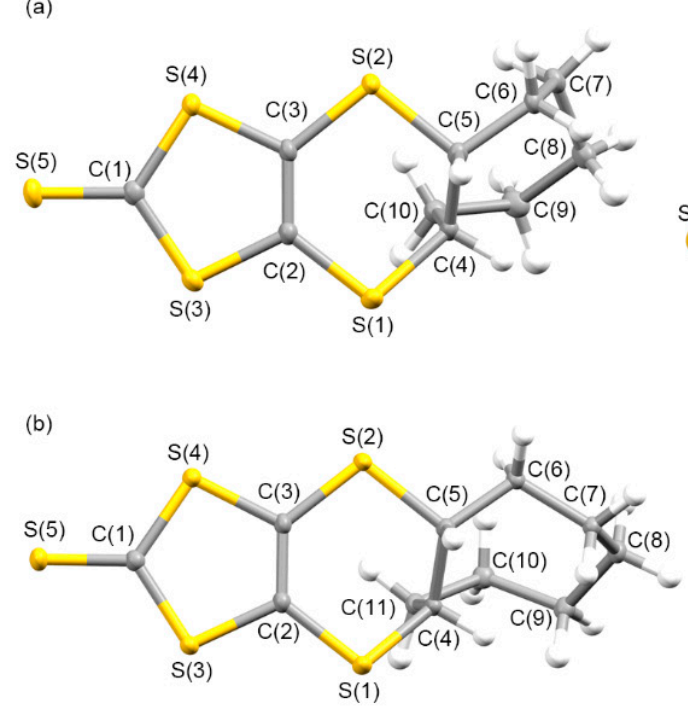
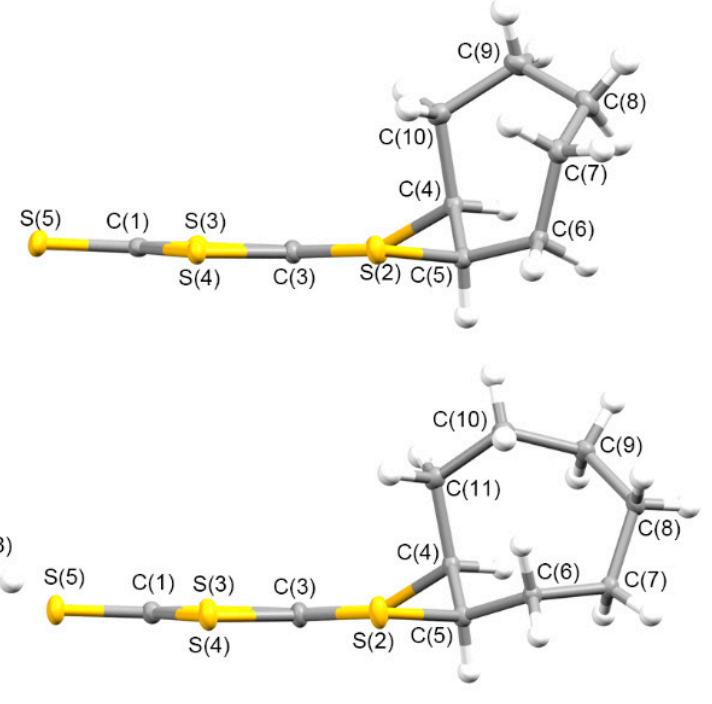
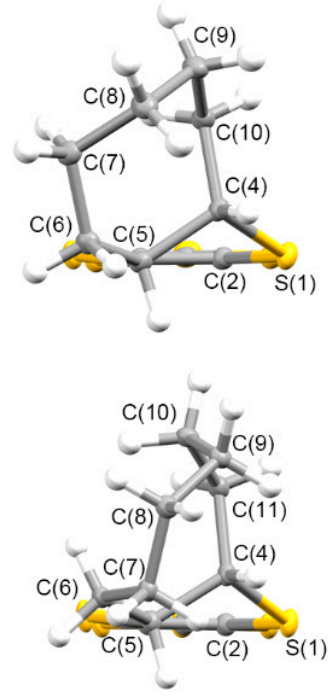

Figure 2. Molecular structures of (a) L3 and (b) L4 along the vertical, parallel, and end-on directions on the $\mathrm{C}_{3} \mathrm{~S}_{5}$ molecular plane with atom labels.

\subsubsection{Molecular and Crystal Structures of Neutral Complexes 5-8}

We successfully obtained single crystals of the neutral complexes that were suitable for X-ray crystallographic analysis by recrystallization from $\mathrm{CS}_{2}$ solutions of complexes 5-8. The synthetic procedure for the neutral complexes is shown in Scheme 3. The precursors of L1-L4 formed cis-oriented $(R, S)$ conformations around the cycloalkylene groups due to the $[2+4]$ cycloadditions. Using the synthetic procedures shown in Scheme 3, Monoanionic complexes 1-4 were obtained as mixtures, including diastereomeric isomers $\left(\mathrm{Bu}_{4} \mathrm{~N}\right)$ \{trans[Ni(cis-Cn-dddt $\left.\left.)_{2}\right]\right\}$ and $\left.\left.\left(\mathrm{Bu}_{4} \mathrm{~N}\right)\{\text { cis-[Ni(cis-Cn-dddt })_{2}\right]\right\}$, due to the conformations between the two cycloalkylene groups in the molecules. The oxidation of Monoanionic complexes 1-4 resulted in the formation of mixtures of diastereomeric isomers for neutral complexes 5-8 (Scheme 4). From the recrystallization processes, single crystals of neutral complexes 5-8 were formed by the trans-isomers. 


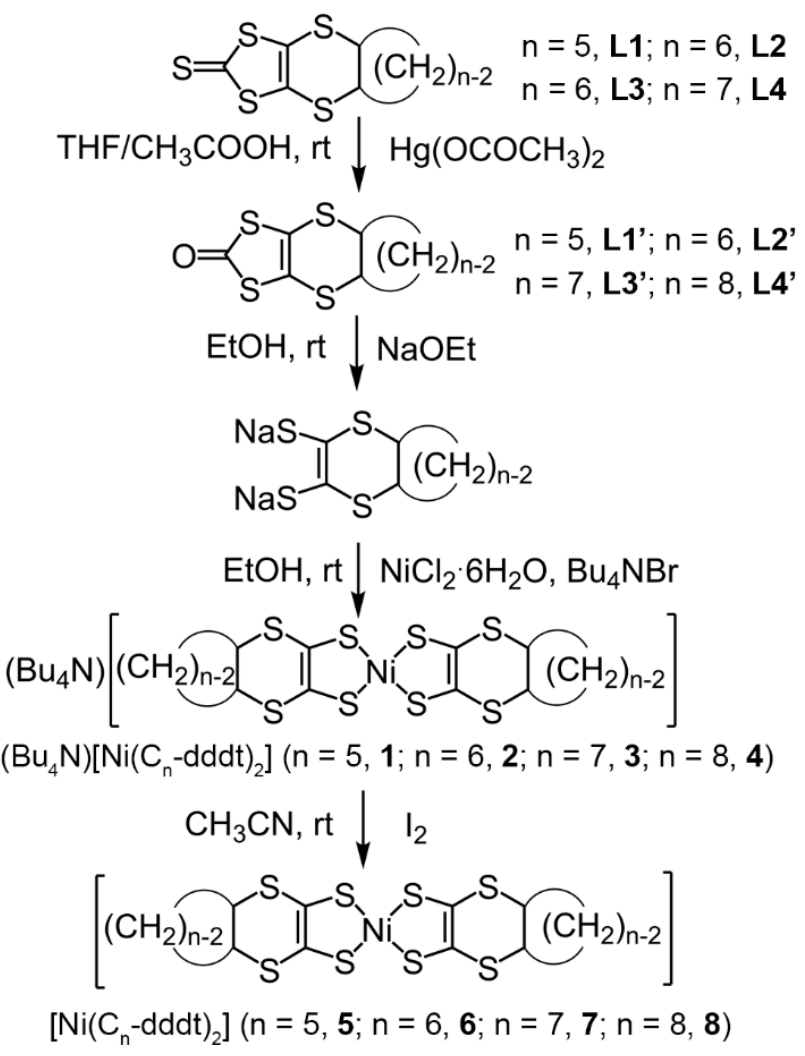

Scheme 3. Synthetic procedure of neutral $\left[\mathrm{Ni}(\mathrm{Cn}-\mathrm{dddt})_{2}\right]$ complexes.

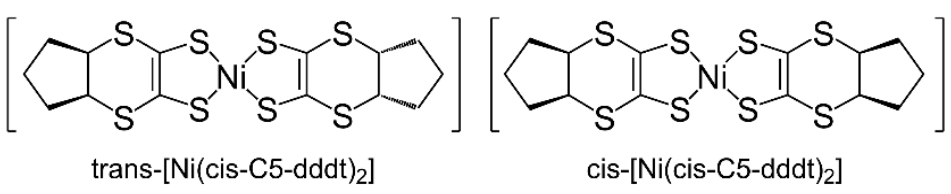

Scheme 4. Diastereomeric isomers of the trans- and cis-[Ni(cis-C5-dddt $\left.)_{2}\right]$ complexes.

The selected bond lengths and angles of the neutral complexes in crystals 5-8 are summarized in Table 5. In molecules of 5-8, square planar co-ordinations were constructed around the $\mathrm{Ni}$ atoms, similar to previously reported square planar $\mathrm{Ni}$-dithiolene complexes such as [Ni(dddt $\left.)_{2}\right]$ in a neutral state [84-91].

Table 5. Selected bond lengths and angles of neutral complexes 5-8.

\begin{tabular}{ccccc}
\hline & 5 & $\mathbf{6}$ & $\mathbf{7}$ & $\mathbf{8}$ \\
\hline $\mathrm{N}(1)-\mathrm{S}(1)$ & $2.1291(4)$ & $2.134(2)$ & $2.1350(4)$ & $2.1341(18)$ \\
$\mathrm{Ni}(1)-\mathrm{S}(2)$ & $2.1340(4)$ & $2.134(2)$ & $2.1343(4)$ & $2.1404(17)$ \\
$\mathrm{Ni}(1)-\mathrm{S}(5)$ & & $2.137(2)$ & & \\
$\mathrm{Ni}(1)-\mathrm{S}(6)$ & & $2.138(2)$ & & \\
$\mathrm{S}(1)-\mathrm{C}(1)$ & $1.7147(15)$ & $1.705(8)$ & $1.7143(15)$ & $1.719(7)$ \\
$\mathrm{S}(2)-\mathrm{C}(2)$ & $1.7153(15)$ & $1.716(9)$ & $1.7084(16)$ & $1.708(7)$ \\
$\mathrm{S}(3)-\mathrm{C}(1)$ & $1.7406(15)$ & $1.736(9)$ & $1.7393(16)$ & $1.748(7)$ \\
$\mathrm{S}(4)-\mathrm{C}(2)$ & $1.7406(15)$ & $1.733(9)$ & $1.7418(15)$ & \\
$\mathrm{S}(5)-\mathrm{C}(9)$ & & $1.715(9)$ & & \\
$\mathrm{S}(6)-\mathrm{C}(10)$ & & $1.699(9)$ & & \\
$\mathrm{S}(7)-\mathrm{C}(9)$ & & $1.739(8)$ & & \\
$\mathrm{S}(8)-\mathrm{C}(10)$ & & $1.755(9)$ & &
\end{tabular}


Table 5. Cont.

\begin{tabular}{|c|c|c|c|c|}
\hline & 5 & 6 & 7 & 8 \\
\hline$S(3)-C(3)$ & $1.8239(15)$ & $1.819(9)$ & $1.8486(15)$ & $1.829(7)$ \\
\hline$S(4)-C(4)$ & $1.8126(15)$ & $1.823(9)$ & $1.8291(16)$ & $1.820(7)$ \\
\hline$C(1)-C(2)$ & $1.386(2)$ & $1.413(12)$ & $1.389(2)$ & $1.380(10)$ \\
\hline$C(3)-C(4)$ & $1.524(2)$ & $1.549(12)$ & $1.525(2)$ & $1.508(10)$ \\
\hline$S(7)-C(11)$ & & $1.818(9)$ & & \\
\hline$S(8)-C(12)$ & & $1.832(9)$ & & \\
\hline$C(9)-C(10)$ & & $1.400(12)$ & & \\
\hline$C(11)-C(12)$ & & $1.523(12)$ & & \\
\hline $\mathrm{S}(1)-\mathrm{Ni}(1)-\mathrm{S}(2)$ & $91.652(14)$ & $91.79(10)$ & $91.959(15)$ & $91.68(7)$ \\
\hline $\mathrm{S}(5)-\mathrm{Ni}(1)-\mathrm{S}(6)$ & & $91.50(9)$ & & \\
\hline $\mathrm{S}(1)-\mathrm{Ni}(1)-\mathrm{S}\left(2^{\prime}\right)^{\mathrm{a})}$ & $88.347(14)$ & & $88.040(15)$ & $88.32(7)$ \\
\hline $\mathrm{S}(1)-\mathrm{Ni}(1)-\mathrm{S}(5)$ & & $88.79(9)$ & & \\
\hline $\mathrm{S}(1)-\mathrm{Ni}(1)-\mathrm{S}(6)$ & & $87.97(9)$ & & \\
\hline$C(1)-C(2)-S(2)$ & $119.03(11)$ & $118.3(7)$ & $119.86(12)$ & 119.5(5) \\
\hline$C(1)-C(2)-S(4)$ & $127.43(12)$ & $127.8(7)$ & $122.23(12)$ & $126.2(5)$ \\
\hline$C(2)-C(1)-S(1)$ & $119.29(11)$ & $119.4(7)$ & $118.98(12)$ & 119.5(5) \\
\hline$C(2)-C(1)-S(3)$ & $126.84(12)$ & $125.6(7)$ & $126.44(12)$ & $126.6(5)$ \\
\hline$C(9)-C(10)-S(6)$ & & $120.3(7)$ & & \\
\hline$C(9)-C(10)-S(8)$ & & $125.6(7)$ & & \\
\hline$C(10)-C(9)-S(5)$ & & $117.8(6)$ & & \\
\hline$C(10)-C(9)-S(7)$ & & $128.3(7)$ & & \\
\hline
\end{tabular}

a) The $S\left(2^{\prime}\right)$ atoms were positioned by the following symmetry operations of $S(2)$ atoms: (2-x, 1-y, 1-z) for 5, (1-x, $1-y,-z)$ for 7 , and (-x, 1-y, 1-z) for 8.

Figure 3 presents the molecular structure of 5 . One half of the trans-[Ni(cis-C5-dddt) 2 ] molecule was crystallographically independent with an inversion center on the nickel atom in the crystals of 5 . The torsion angles around the fused cyclopentylene group of the molecule were $45.93^{\circ}, 42.06^{\circ}$, and $-62.81^{\circ}$ for $\mathrm{C}(1)-\mathrm{S}(3)-\mathrm{C}(3)-\mathrm{C}(4), \mathrm{C}(2)-\mathrm{S}(4)-\mathrm{C}(4)-\mathrm{C}(3)$, and $\mathrm{S}(3)-\mathrm{C}(3)-\mathrm{C}(4)-\mathrm{S}(4)$, respectively. The approximate geometry of the $\left[\mathrm{Ni}(\mathrm{dddt})_{2}\right]$ moiety in crystal 5 was highly similar to those of an anionic [Ni(dddt) $]^{-}$molecule [92]. The cyclopentylene ring of 5 adopted a folded conformation from the [Ni(dddt $\left.)_{2}\right]$ moiety with the trans-orientation, which is different from the conformation observed in $\left(\mathrm{Ph}_{4} \mathrm{P}\right)\{$ trans[Ni(cis-C5-dddt) $\left.\left.{ }_{2}\right]\right\}$ (an envelope conformation) [93].
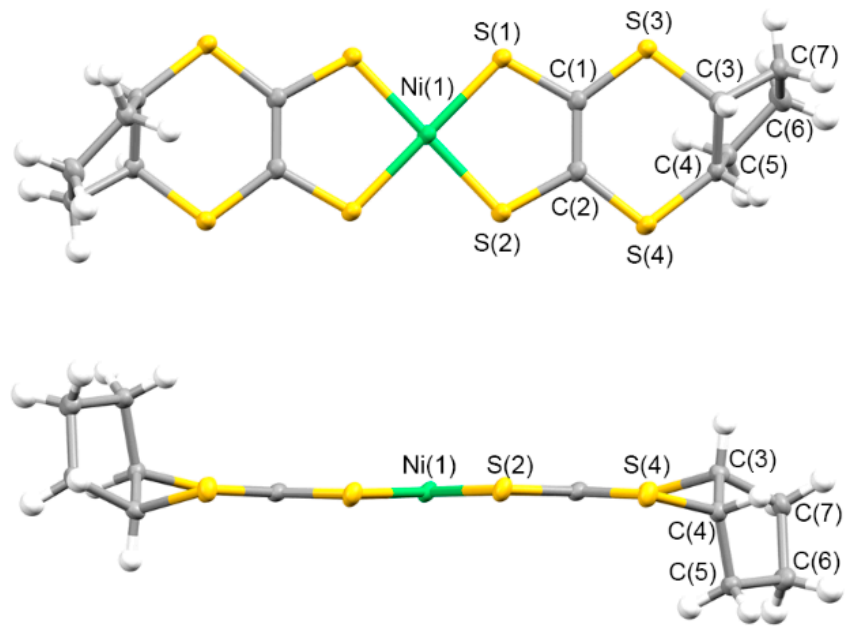

Figure 3. Molecular structure of 5 along the vertical and parallel directions on the molecular plane, with atom labels.

The packing diagrams of 5 are shown in Figure 4. Due to the folded geometry, the 
columnar structures of the complex were restricted. The shortest $\mathrm{Ni}-\mathrm{Ni}$ distance was $6.283 \AA$, which was the length of the $a$ axis. The intermolecular $S$...S contacts shorter than the sum of the van der Waals radius $(3.70 \AA$ ) were observed between the $S(1)-S(1)$ atoms $\left(3.574 \AA\right.$ ) and $S(1)-S\left(4^{\prime}\right)$ atoms (3.604 $\AA$ ), which formed a three-dimensional network structure in crystal 5.

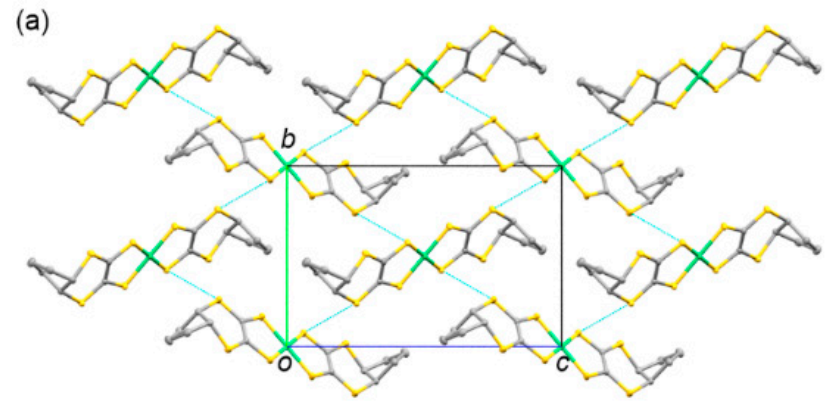

(b)

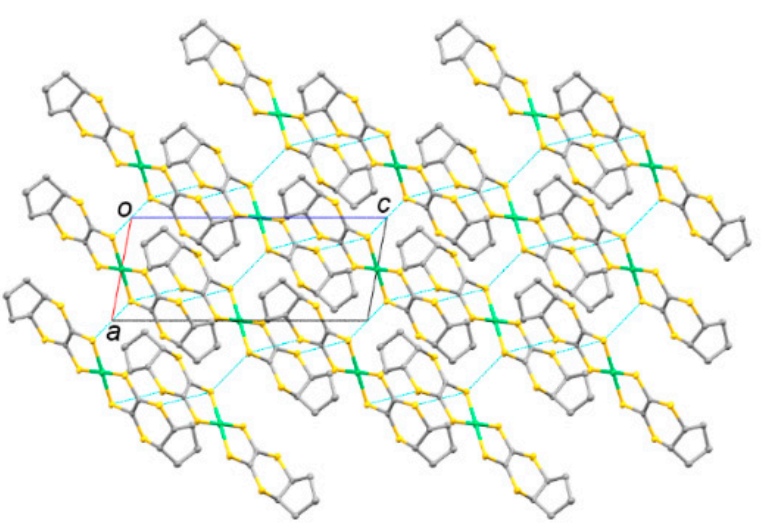

(c)

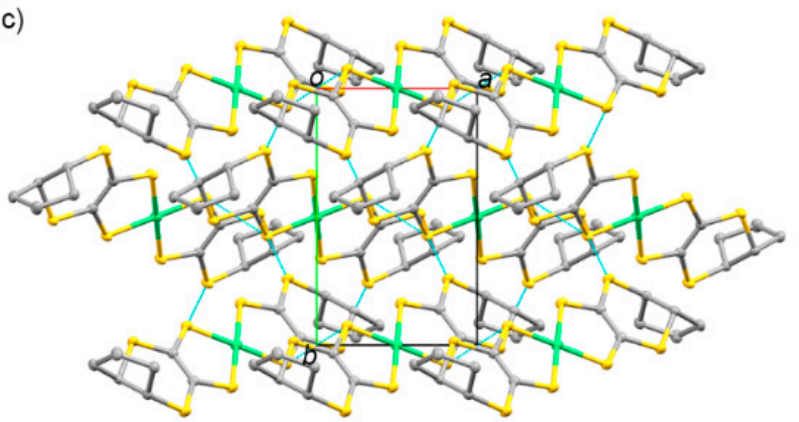

Figure 4. Crystal structures of $\mathbf{5}$ viewed along the (a) $a,(\mathbf{b}) b$, and (c) $c$ axes. Hydrogen atoms are omitted for clarity. The blue dashed lines indicate the intermolecular S...S contacts shorter than the sum of the van der Waals radius (3.70 ̊).

The molecular structure of compound 6 is shown in Figure 5. One trans-[Ni(cis-C6$\mathrm{dddt})_{2}$ ] molecule was present in the asymmetric unit of the crystal. The torsion angles around the fused cyclohexylene group of the molecule were $43.79^{\circ},-68.30^{\circ}$, and $-62.81^{\circ}$ for $C(1)-S(3)-C(3)-C(4), C(2)-S(4)-C(4)-C(3)$, and $S(3)-C(3)-C(4)-S(4)$, respectively. The corresponding torsion angles in the opposite site of the molecule were $-45.87^{\circ},-47.04^{\circ}$, and $66.65^{\circ}$ for $C(9)-S(7)-C(11)-C(12), C(10)-S(8)-C(12)-C(11)$, and $S(7)-C(11)-C(12)-S(8)$, respectively. The stable chair-type configurations of the cyclohexylene groups were observed. However, the folded conformations of the cyclohexylene groups from the planar [Ni(dddt $)_{2}$ ] core were different from those of $\mathbf{L} \mathbf{4}$, which exhibited larger flexures around the terminal S-C bonds (Figure 1). 

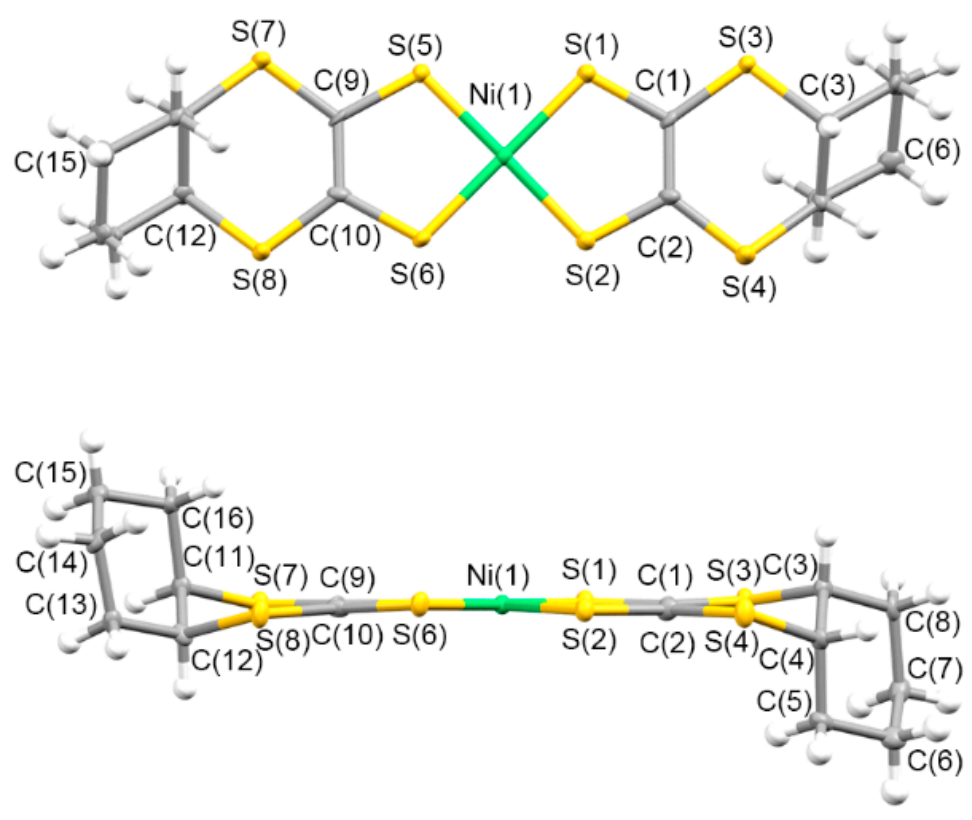

Figure 5. Molecular structure of 6 along the vertical and parallel directions on the molecular plane with atom labels.

A similar molecular geometry of trans-[Ni(cis-C6-dddt) 2 ] was reported by Bai et al. [94]. However, the packing motif of crystal $\mathbf{6}$ was significantly different from that of the reported crystal constructed by the centrosymmetric molecular arrangement of trans-[Ni(cis-C6$\mathrm{dddt})_{2}$ ] with an inversion center on the nickel atom. In the case of crystal 6, a noncentrosymmetric molecular arrangement with a helix axis along the $b$ axis formed by the trans-[Ni(cis-C6-dddt) $\left.{ }_{2}\right]$ molecules was observed (Figure 6). The cyclohexylene rings prevented the formation of stacks of the complexes and intermolecular interactions through the $S$...S contacts. The shortest intermolecular S...S distance was $3.749 \AA$ A between S(1) and $\mathrm{S}(8)$. The shortest $\mathrm{Ni}-\mathrm{Ni}$ distance was $8.030 \AA$, which was the length of the a axis.

One half of the trans-[Ni(cis-C7-dddt) $\left.{ }_{2}\right]$ molecule was present in the asymmetric unit in Crystal 7 (Figure 7). The twist chair-type configurations of the cycloheptylene groups in $\mathbf{L} \mathbf{3}$ were maintained in the crystals after the coordination reaction of $\mathbf{L 3}^{\prime}$ and the nickel source (Scheme 3). The twist chair-type configurations of the cycloheptylene groups around the terminal S-C bonds in the molecule exhibited larger flexures (Figure 2), with torsion angles around the fused cycloheptylene group of $10.13^{\circ}, 68.04^{\circ}$, and $-55.70^{\circ}$ for $C(1)-S(3)-C(3)-C(4), C(2)-S(4)-C(4)-C(3)$, and $S(3)-C(3)-C(4)-S(4)$, respectively. Figure 8 presents the crystal structure of 7 . The cycloheptylene moieties were in contact along the $c$ axis. There was no intermolecular $\mathrm{S} \cdots \mathrm{S}$ contact, given that the $\left[\mathrm{Ni}(\mathrm{dddt})_{2}\right]$ cores were completely separated by the steric hindrance of the cycloheptane moieties. 
(a)

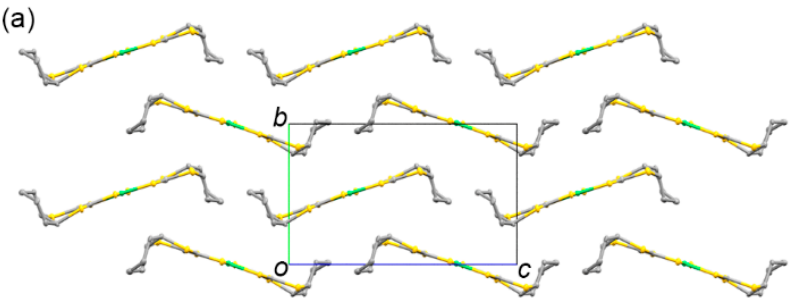

(b)

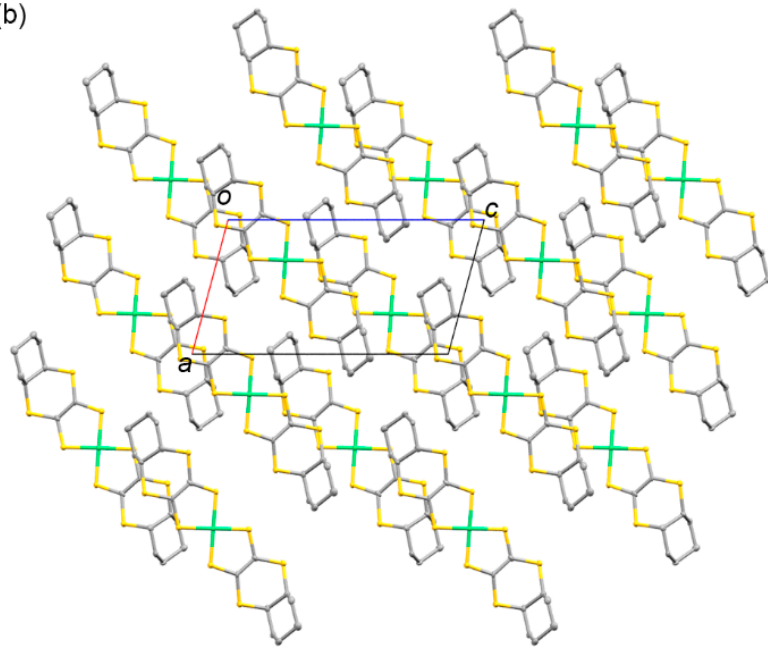

(c)

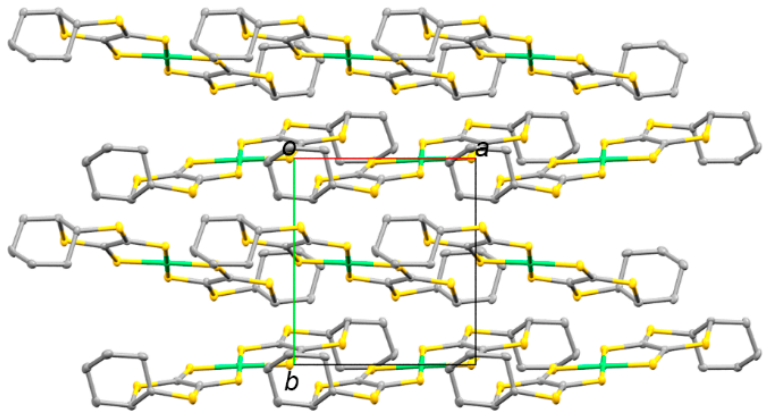

Figure 6. Crystal structure of $\mathbf{6}$ along the (a) $a$, (b) $b$, and (c) $c$ axes. Hydrogen atoms are omitted for clarity.
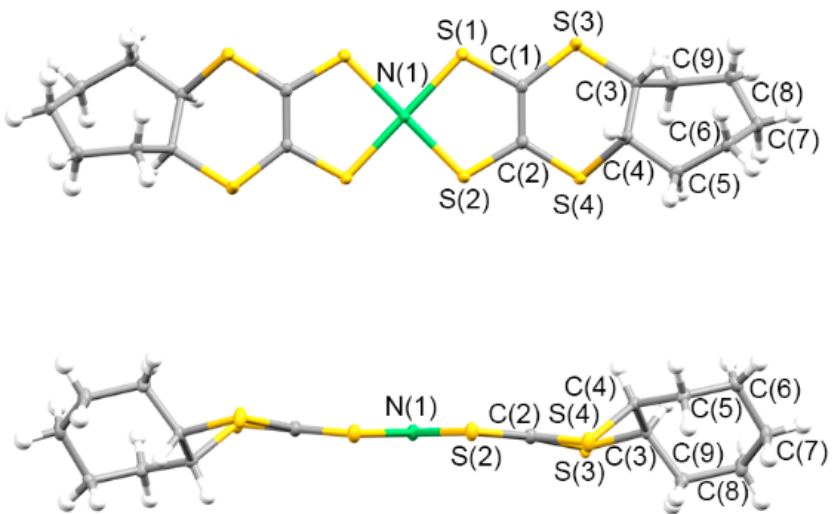

Figure 7. Molecular structure of 7 along the vertical and parallel directions on the molecular plane with atom labels. 

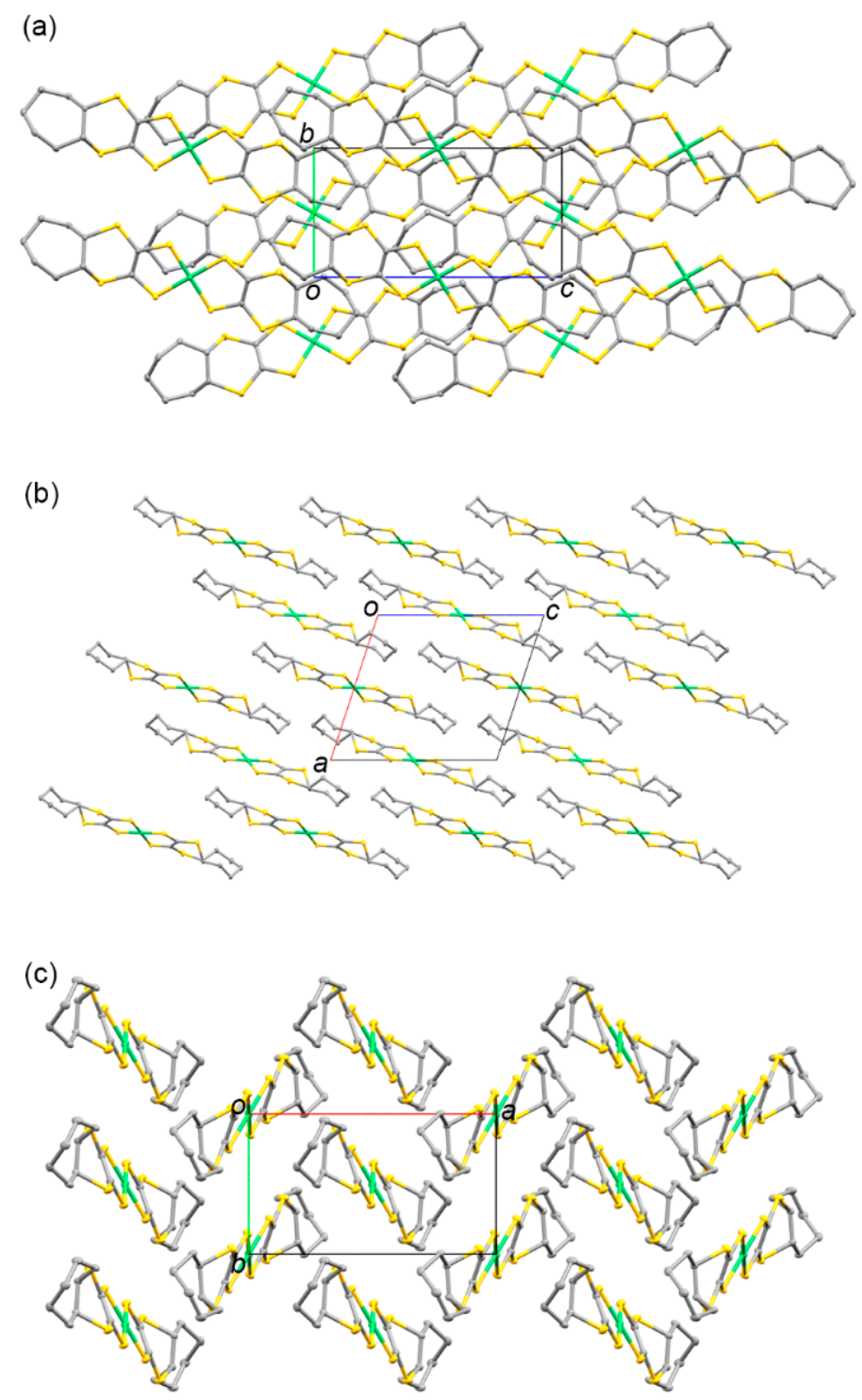

Figure 8. Crystal structure of 7 along the (a) $a$, (b) $b$, and (c) $c$ axes. Hydrogen atoms are omitted for clarity.

Figures 9 and 10 present the molecular and crystal structures of $\mathbf{8}$. The centrosymmetric crystal was formed by one-half of the trans-[Ni(cis-C8-dddt) 2$]$ molecule in the asymmetric unit. The boat-chair-type configurations of the cyclooctylene groups formed in $\mathbf{L} 4$ remained in molecule 6 with torsion angles of $54.74^{\circ}, 46.88^{\circ}$, and $-70.84^{\circ}$ for $\mathrm{C}(1)-\mathrm{S}(1)-\mathrm{C}(3)-\mathrm{C}(4)$, $\mathrm{C}(2)-\mathrm{S}(4)-\mathrm{C}(4)-\mathrm{C}(3)$, and $\mathrm{S}(3)-\mathrm{C}(3)-\mathrm{C}(4)-S(4)$, respectively. One-dimensional columns along the $a$ axis were constructed by ring-over-ring overlaps between the molecules sliding to the molecular longitudinal axis. There were no intercolumnar interactions through the S-S contacts. The shortest distance was $3.775 \AA$ A between $S(2)$ and $S\left(3^{\prime}\right)$ in the column. The columns interacted through the side-by-side intermolecular $S$...S contacts between $S(3)$ and $S\left(3^{\prime}\right)$ with a distance of $3.444 \AA$. 

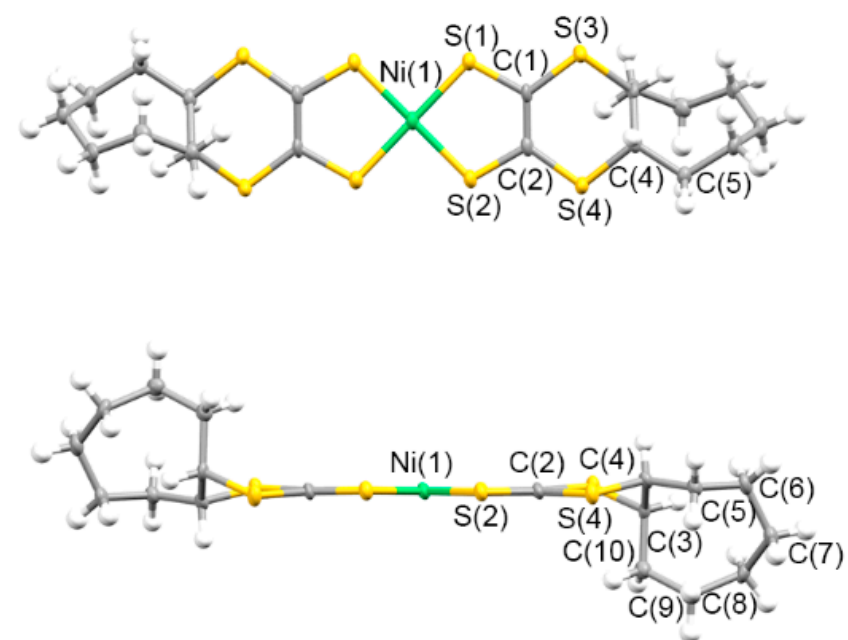

Figure 9. Molecular structure of 8 along the vertical and parallel directions on the molecular plane with atom labels.

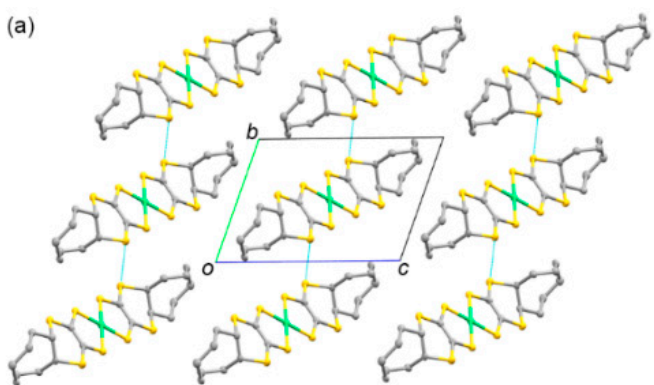

(b)

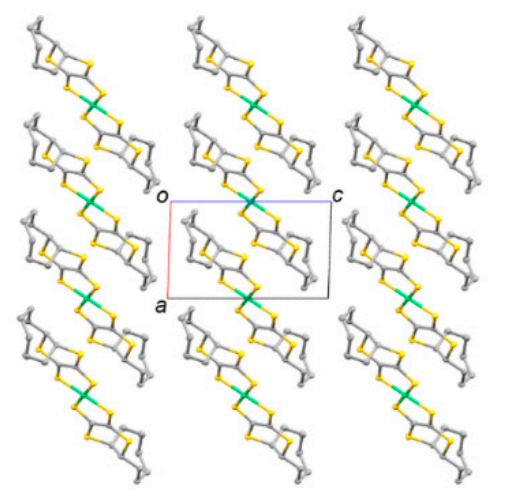

(c)

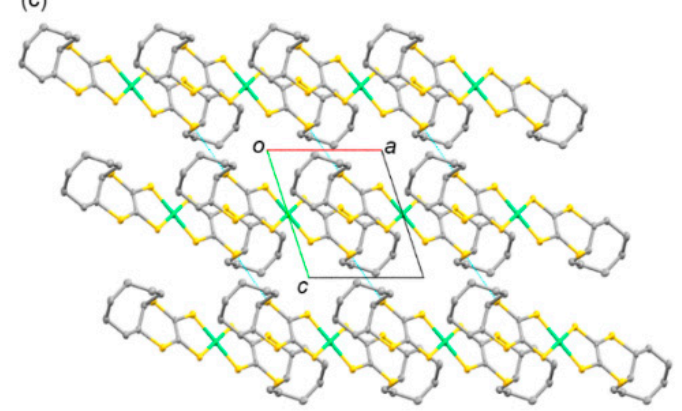

Figure 10. Crystal structure of $\mathbf{8}$ along the (a) $a,(\mathbf{b}) b$, and (c) $c$ axes. Hydrogen atoms are omitted for clarity. The blue dashed lines indicate the intermolecular $\mathrm{S}$...S contacts shorter than the sum of the van der Waals radius (3.70 ̊). 


\subsection{Electrochemical Properties of $\mathbf{1 - 4}$}

Cyclic voltammograms of monoanionic complexes $1-4$ and $\left(\mathrm{Bu}_{4} \mathrm{~N}\right)\left[\mathrm{Ni}(\mathrm{dddt})_{2}\right]$ in $\mathrm{MeCN}$ were obtained (Figure 1). The voltammograms of $\left(\mathrm{Bu}_{4} \mathrm{~N}\right)\left[\mathrm{Ni}(\mathrm{dddt})_{2}\right]$ exhibited two quasi-reversible couples and one irreversible redox couple in the recorded region (Figure 1). The quasi-reversible redox peaks were assigned to $\left[\mathrm{Ni}(\mathrm{dddt})_{2}\right]^{0} /\left[\mathrm{Ni}(\mathrm{dddt})_{2}\right]^{+}$ $\left(E_{1 / 2}{ }^{1}=-1.24 \mathrm{~V}\right)$ and $\left[\mathrm{Ni}(\mathrm{dddt})_{2}\right]^{-} /\left[\mathrm{Ni}(\mathrm{dddt})_{2}\right]^{0}\left(E_{1 / 2}{ }^{2}=-1.02 \mathrm{~V}\right)$ (Figure 11a). An irreversible oxidation peak was observed at $0.28 \mathrm{~V}$, which indicates a reduction process between the dianionic $\left[\mathrm{Ni}(\mathrm{dddt})_{2}\right]^{-}$and monoanionic $\left[\mathrm{Ni}(\mathrm{dddt})_{2}\right]^{2-}$ states. The electrochemical features of $\mathbf{1}-\mathbf{4}$ were similar to those of $\left(\mathrm{Bu}_{4} \mathrm{~N}\right)\left[\mathrm{Ni}(\mathrm{dddt})_{2}\right]$. The redox potentials $E_{1 / 2}{ }^{1}\left(\left[\mathrm{Ni}\left(\mathrm{C}_{\mathrm{n}}-\mathrm{dddt}\right)_{2}\right]^{0} /\left[\mathrm{Ni}\left(\mathrm{C}_{\mathrm{n}}-\mathrm{dddt}\right)_{2}\right]^{+}\right)$and $\left.E_{1 / 2}{ }^{2}\left(\left[\mathrm{Ni}\left(\mathrm{C}_{\mathrm{n}}-\mathrm{dddt}\right)_{2}\right]^{-} \mathrm{Ni}\left(\mathrm{C}_{\mathrm{n}}-\mathrm{dddt}\right)_{2}\right]^{0}\right)$ of 1-4 are summarized in Table 6. Potentials $E_{1}$ and $E_{2}$ were correlated to the donor abilities of the complexes. The $\Delta E\left(=E_{1 / 2}{ }^{2}-E_{1 / 2}{ }^{1}\right)$ values could be considered a measure of the on-site Coulomb energies $[47,64]$. Based on the $E_{1 / 2}{ }^{1}, E_{1 / 2}{ }^{2}$, and $\Delta E$ values, the complexes with fused cycloalkanes maintained the donor ability and on-site Coulomb energy of $\left(\mathrm{Bu}_{4} \mathrm{~N}\right)\left[\mathrm{Ni}(\mathrm{dddt})_{2}\right]$.

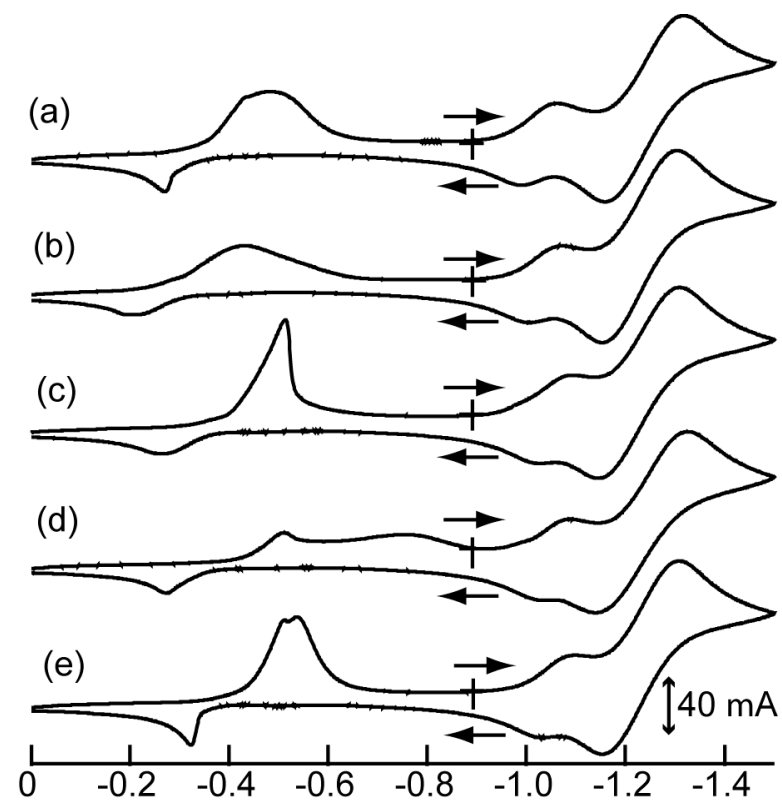

Figure 11. Cyclic voltammograms of (a) $\left(\mathrm{Bu}_{4} \mathrm{~N}\right)\left[\mathrm{Ni}(\mathrm{dddt})_{2}\right]$, (b) 1, (c) 2, (d) 3, and (e) 4. Conditions: $\mathrm{MeCN}\left(1 \times 10^{-3} \mathrm{M}\right)$, supporting electrolyte: $\left(\mathrm{Bu}_{4} \mathrm{~N}\right)\left(\mathrm{ClO}_{4}\right)(0.1 \mathrm{M})$, scan rate: $100 \mathrm{mV} / \mathrm{s}$, reference electrode: $\mathrm{Ag} / \mathrm{Ag}^{+}$, counter electrode: Pt wire, working electrode: glassy carbon at room temperature.

Table 6. Redox potentials $E_{1 / 2}{ }^{1} / \mathrm{V}(0,-1), E_{1 / 2}{ }^{2} / \mathrm{V}(-1,-2)$, and $\Delta E\left(=E_{1 / 2}{ }^{2}-E_{1 / 2}{ }^{1}\right) / \mathrm{V}$ of $\left(\mathrm{Bu}_{4} \mathrm{~N}\right)\left[\mathrm{Ni}(\mathrm{dddt})_{2}\right]$ and Complexes 1-4.

\begin{tabular}{cccc}
\hline & $\boldsymbol{E}_{\mathbf{1 / 2}}{ }^{\mathbf{1} / \mathbf{V}}$ & $\boldsymbol{E}_{\mathbf{1 / 2}}{ }^{2} / \mathbf{V}$ & $\Delta \boldsymbol{E} / \mathbf{V}$ \\
\hline$(\mathrm{Bu} 4 \mathrm{~N})\left[\mathrm{Ni}(\mathrm{dddt})_{2}\right]$ & -1.24 & -1.02 & 0.22 \\
$\mathbf{1}$ & -1.23 & -1.03 & 0.20 \\
$\mathbf{2}$ & -1.23 & -1.05 & 0.18 \\
$\mathbf{3}$ & -1.23 & -1.05 & 0.18 \\
$\mathbf{4}$ & -1.23 & -1.06 & 0.17 \\
\hline
\end{tabular}

Conditions: $\mathrm{MeCN}\left(1 \times 10^{-3} \mathrm{M}\right)$, supporting electrolyte: $\left(\mathrm{Bu}_{4} \mathrm{~N}\right)\left(\mathrm{ClO}_{4}\right)(0.1 \mathrm{M})$, scan rate: $100 \mathrm{mV} / \mathrm{s}$, reference electrode: $\mathrm{Ag} / \mathrm{Ag}^{+}$, counter electrode: Pt wire, working electrode: glassy carbon at room temperature.

\subsection{Electronic Absorption Spectra of 1-8}

The electronic absorption spectra of monoanionic complexes 1-4 and neutral complexes 5-8 in $\mathrm{CH}_{2} \mathrm{Cl}_{2}$ were measured. Monoanionic complexes 1-4 exhibited a strong and broad absorption band at approximately $1036-1201 \mathrm{~nm}$ in the near-infrared region, which 
can be attributed to a $\pi-\pi *$ transition between their HOMOs and LUMOs (Table 7) $[95,96]$. With respect to neutral complexes 5-8, the HOMO-LUMO absorption bands were shifted to the higher energy region (982-1040 nm), which corresponds to the energy gap between HOMO-1 and the HOMOs of the monoanionic complexes due to the weak shoulder absorptions observed at approximately $1000 \mathrm{~nm}$. For example, monoanionic complex 4 exhibited two absorptions at $1201 \mathrm{~nm}$ and $1040 \mathrm{~nm}$, which can be attributed to the HOMO-LUMO and HOMO-1 to HOMO gaps, respectively (Figure 12). The HOMO-LUMO gaps of the neutral complexes estimated by the spectra were within the range $1.19-1.26 \mathrm{eV}$. The spectroscopic behaviors of the complexes were similar to those of other bis(ethylene-1,2-dithiolato) complexes and $\mathrm{M}\left(\mathrm{S}_{2} \mathrm{C}_{2} \mathrm{R}_{2}\right)_{2}[85-89,93,94,97,98]$.

Table 7. Wavelength at absorption maxima $\left(\lambda_{\max }\right)$ and absorption coefficients $(\varepsilon)$ for the $\pi-\pi^{*}$ transitions of 1-8 in $\mathrm{CH}_{2} \mathrm{Cl}_{2}$.

\begin{tabular}{cccc}
\hline & $\lambda_{\text {max }} / \mathbf{n m}$ & Energy gap/eV & $\varepsilon / \mathbf{d m}^{\mathbf{3}} \mathbf{~ m o l}^{-\mathbf{1}}$ \\
\hline $\mathbf{1}$ & 1036 & 1.19 & 12,000 \\
$\mathbf{2}$ & 1198 & 1.03 & 10,000 \\
$\mathbf{3}$ & 1144 & 1.08 & 13,000 \\
$\mathbf{4}$ & 1201 & 1.03 & 13,000 \\
$\mathbf{5}$ & 982 & 1.26 & 32,000 \\
$\mathbf{6}$ & 1035 & 1.20 & 32,000 \\
$\mathbf{7}$ & 1031 & 1.20 & 39,000 \\
$\mathbf{8}$ & 1040 & 1.19 & 49,000 \\
\hline
\end{tabular}

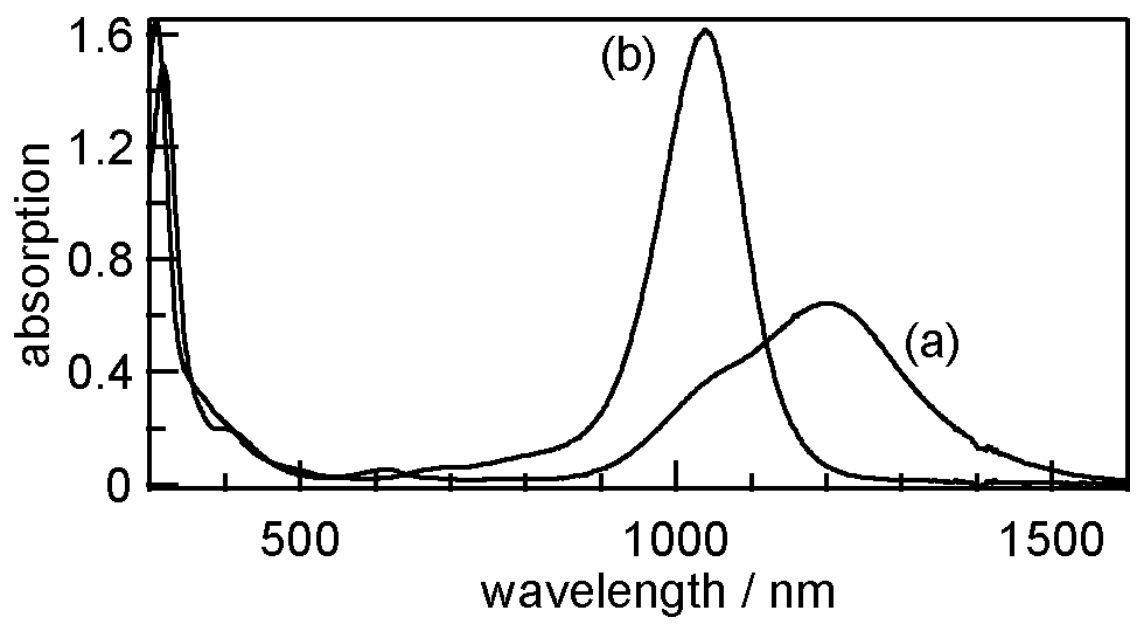

Figure 12. Electronic absorption spectra of (a) $4\left(4.82 \times 10^{-5} \mathrm{M}\right)$ and (b) $8\left(3.40 \times 10^{-5} \mathrm{M}\right)$ in $\mathrm{CH}_{2} \mathrm{Cl}_{2}$ solutions.

\subsection{Structures and Physical Properties of Radical Cation Crystals $\mathbf{9}$ and $\mathbf{1 0}$}

\subsubsection{Molecular and Crystal Structures of $\mathbf{9}$ and $\mathbf{1 0}$}

The electrochemical oxidation of $\mathrm{CH}_{2} \mathrm{Cl}_{2}$ solutions, including neutral complex 5 and the corresponding supporting electrolytes $\left(\mathrm{Bu}_{4} \mathrm{~N}\right) \mathrm{X}\left(\mathrm{X}=\mathrm{ClO}_{4}^{-}\right.$and $\left.\mathrm{PF}_{6}{ }^{-}\right)$, resulted in the crystallization of 2:1 [Ni(cis-C5-dddt) $\left.{ }_{2}\right]_{2}(\mathrm{X})$ salts. The donor/acceptor ratios of the 2:1 crystals were different from those of the previously reported radical cation crystals based on the $\left[\mathrm{Ni}(\mathrm{dddt})_{2}\right]$ complex without bulky substituents, constructing the 3:2 crystals of $\left[\mathrm{Ni}(\mathrm{dddt})_{2}\right]_{3}(\mathrm{~A})_{2}\left(\mathrm{~A}=\mathrm{AuBr}_{2}{ }^{-}, \mathrm{BF}_{4}{ }^{-}, \mathrm{ClO}_{4}{ }^{-}, \mathrm{HSO}_{4}{ }^{-}\right.$, and $\mathrm{HSeO}_{4}{ }^{-}[55,56,99-103]$. The crystals of 9 and 10 included one crystallographically independent donor and half of the $\mathrm{ClO}_{4}{ }^{-}$or $\mathrm{PF}_{6}{ }^{-}$anions, respectively. Figure 13 and (Supplementary Materials) Figure S1 present the molecular structures of the donors in 9 and 10. In the case of the radical cation crystals, the cis-[Ni(cis-C5-dddt $\left.)_{2}\right]$ conformation was formed preferentially, although the corresponding neutral complex exhibited the trans-[Ni(cis-C5-dddt) 2 ] conformation 
(Scheme 4). The donors exhibited a square planar coordination around the $\mathrm{Ni}$ atoms. Moreover, the bond distances of Ni-S = 2.1438(5)-2.1481(5) $\AA, \mathrm{S}-\mathrm{C}=1.703(2)-1.7077(19) \AA$, and $\mathrm{C}=\mathrm{C}=1.406(3)-1.408(3) \AA$ for 9; and Ni-S = 2.1435(6)-2.1498(6) $\AA, \mathrm{S}-\mathrm{C}=1.702(2)$ 1.705(2) $\AA$, and $\mathrm{C}=\mathrm{C}=1.404(3)-1.414(3) \AA$ for 10 in the $\mathrm{NiS}_{4} \mathrm{C}_{4}$ framework were slightly larger than those of the neutral trans-[Ni(cis-C5-dddt) $)_{2}$. Figure 14 and Figure S2 present the crystal structures of $\mathbf{9}$ and 10. In the crystals, similar molecular arrangements of the donors and anions were observed with a two-fold axis on one of the $\mathrm{Cl}-\mathrm{O}$ and P-F bonds of the anions along the $b$ axis, respectively. In 9 , the perchlorate anions were disordered at the two sites by rotation around the two-fold axis. The cis-[Ni(cis-C5-dddt) $\left.)_{2}\right]$ conformation would induce dimerized structures of the donors in $\mathbf{9}$ and 10, which differ from the molecular arrangement in the cases of the $3: 2$ crystals of $\left[\mathrm{Ni}(\mathrm{dddt})_{2}\right]_{3}(\mathrm{~A})_{2}$ significantly. The dimerized structures of the donors were formed by the S...S contacts ( $3.665 \AA$ and $3.664 \AA$ for 9 and 10 , respectively), and the dimers were arranged into columnar structures through the S...S contacts ( $3.682 \AA$ and $3.556 \AA$ for 9 and 10, respectively) along the $a-c$ axis directions in 9 and 10. Intermolecular side-by-side interactions through the S ...S contacts (3.507-3.637 $\AA$ and 3.500-3.629 $\AA$ for 9 and 10, respectively) between the columns were observed along the $b$ axis, thus providing two-dimensional donor sheets parallel to the $b c$ planes. Although the donor molecule is fused with the bulky cyclopentane moieties, the two-dimensional donor sheet arrangements through the S...S contacts preferentially are constructed in the radical cation crystals, which are also observed in the organic radical cation crystals based on the BEDT-TTF and BETS molecules exhibiting metallic and superconducting behaviors [14-18].
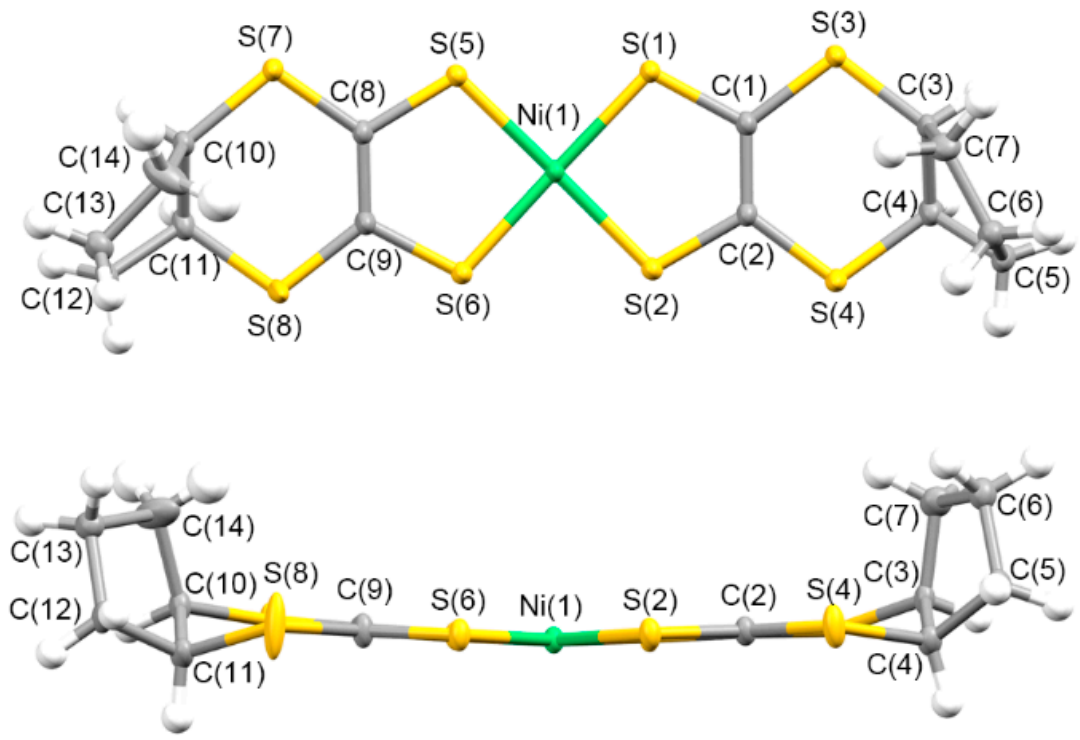

Figure 13. Molecular structure of 9 along the vertical and parallel directions on the molecular plane with atom labels. 
(a)
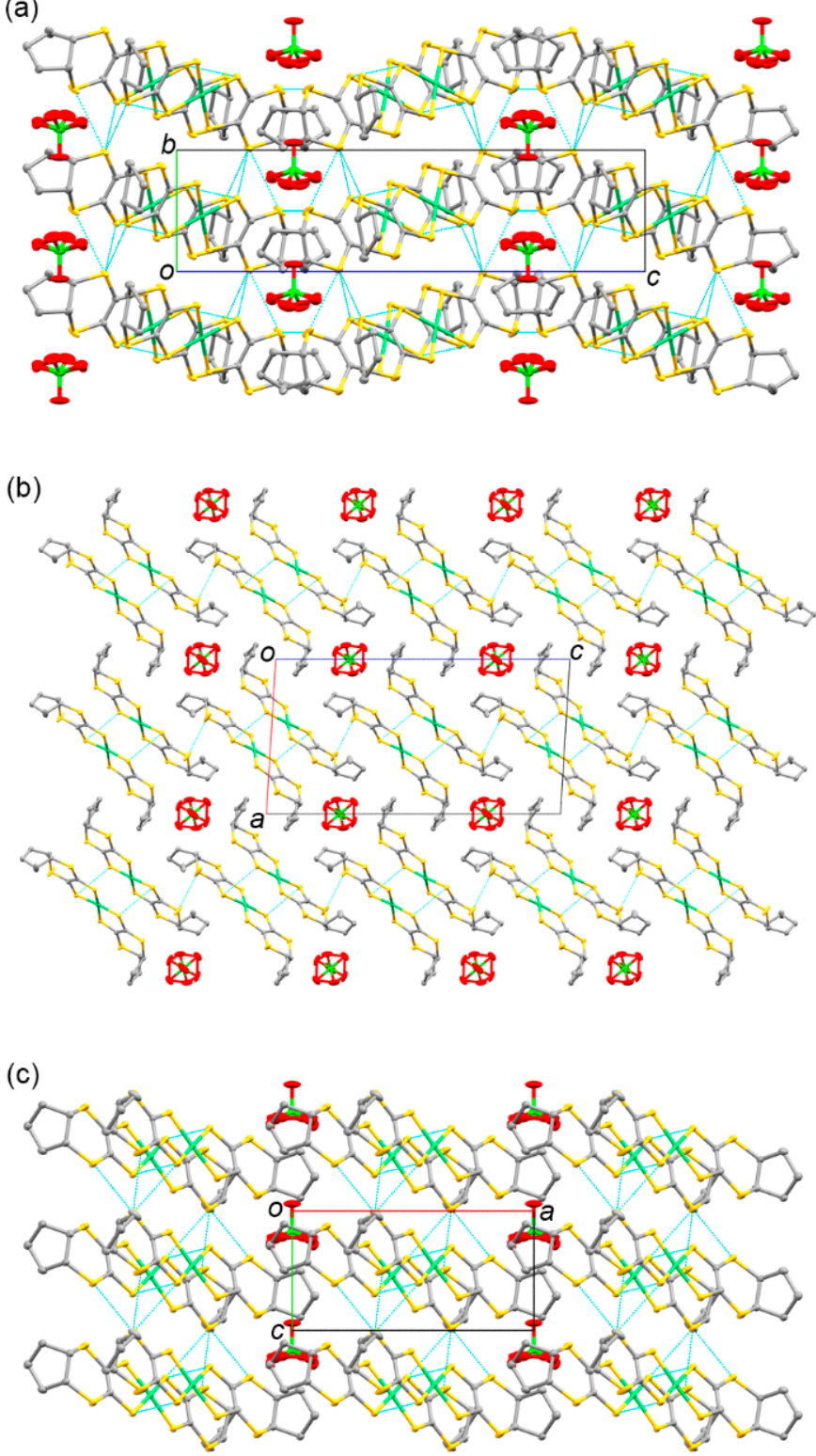

Figure 14. Crystal structure of 9 along (a) the $a,(\mathbf{b}) b$, and (c) $c$ axes. Hydrogen atoms are omitted for clarity. The dashed lines indicate sulfur-sulfur distances shorter than the sum of the van der Waals radius $(<3.7 \AA)$.

\subsubsection{Molecular Orbitals and Energy Band Calculations of $\mathbf{9}$ and $\mathbf{1 0}$}

To reveal the electronic features of the salts, molecular orbitals (MO) and energy band structures were determined using the extended Hückel and tight-binding methods. Figure 15 presents the determined HOMOs and LUMOs of the donor molecules of 9 and 10 in their neutral states. The highly symmetric HOMOs and LUMOs with the nickel $d$ orbitals of the donors were in good agreement with the molecular orbitals of the [M(dddt $\left.)_{2}\right]$ complex calculated based on the first-principles density-functional theory [56-62].

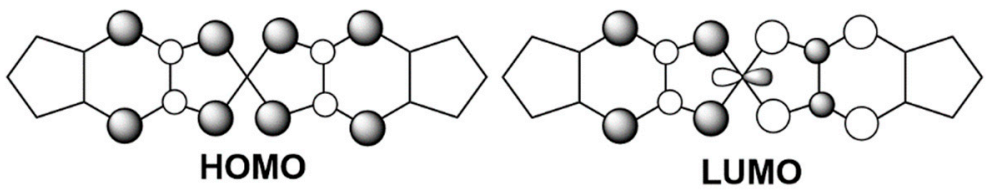

Figure 15. The HOMO and LUMO of $\left[\mathrm{Ni}\left(\mathrm{C}_{5}-\mathrm{dddt}\right)_{2}\right]$. 
The calculated overlap integrals $(S)$ of the crystals between the HOMOs are summarized in Table 8 with a schematic diagram of their donor arrangements. The symbols a1-b4 indicate directions of intermolecular interactions between the donors. Figure S3 presents the corresponding molecular arrangement of the donor molecules viewed along the end-on direction in the crystal. The significant dimerization of the crystals was observed, given that the face-to-face interactions (a2) were significantly stronger than the other interactions (a1) in the columns. Dominant side-by-side interactions (b1 and b4) connected the dimers, thus forming two-dimensional sheets in the crystals. Figure 16 presents the calculated band structure of $\mathbf{9}$, which is similar to that of crystal 10. Both the upper bands crossed the Fermi level, thus forming the small two-dimensional Fermi surfaces of the crystals.

Table 8. Overlap integrals $(S)$ between the HOMOs and a schematic diagram of the donor arrangements for Crystals 9 and $\mathbf{1 0 .}$

\begin{tabular}{|c|c|c|}
\hline$S\left(\times 10^{3}\right)$ & 9 & 10 \\
\hline a1 & -2.7 & -1.9 \\
\hline a2 & -10 & -10 \\
\hline b1 & -6.9 & -3.8 \\
\hline b2 & -0.14 & -0.7 \\
\hline b3 & -0.14 & -0.7 \\
\hline b4 & 1.2 & -0.3 \\
\hline
\end{tabular}

(a)

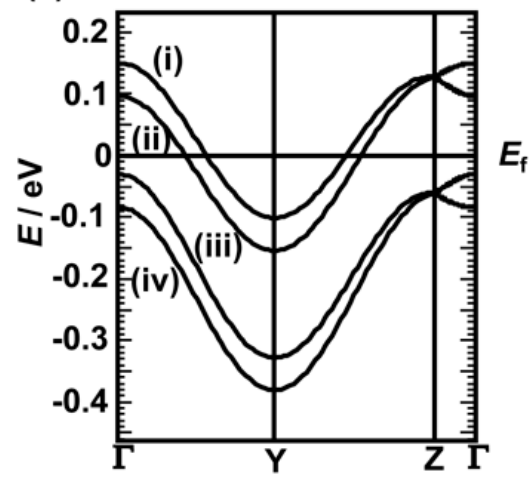

(b)

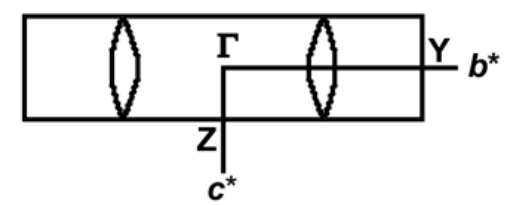

Figure 16. (a) Energy band structure and (b) Fermi surface of 9 . The characters $b^{*}$ and $c^{*}$ denote reciprocal lattice axes.

\subsubsection{Electrical Conductivities and Magnetic Properties of $\mathbf{9}$ and $\mathbf{1 0}$}

The temperature dependence of the resistivities was measured for single crystals of 9 and $10 \mathrm{~K}$ using a standard four-probe direct current (DC) method (Figure 17). The salts exhibited semiconducting behaviors $\left(9: \rho_{\mathrm{rt}}=0.8 \Omega \mathrm{cm}\right.$ and $E_{\mathrm{a}}=0.09 \mathrm{eV} ; 10: \rho_{\mathrm{rt}}=4.0 \Omega \mathrm{cm}$ and $\left.E_{\mathrm{a}}=0.13 \mathrm{eV}\right)$. Although the energy band calculations for 9 and 10 suggested a metallic nature, crystals $\mathbf{9}$ and $\mathbf{1 0}$ exhibited semiconducting behaviors under ambient pressure. The results of the resistivity measurements and the energy band calculations indicate that the crystals forms a Mott insulating state or a spin-singlet state under ambient pres- 
sure [104]. In order to reveal the electronic structures of the crystals, temperature dependence of the resistivities under hydrostatic pressures and magnetic susceptibilities of 9 and 10 were measured. The resistivity measurements under various hydrostatic pressures (0.3-1.8 GPa) exhibited slightly smaller activation energies than those under ambient pressure (9: $\rho_{\mathrm{rt}}=0.2 \Omega \mathrm{cm}$ and $E_{\mathrm{a}}=0.07 \mathrm{eV} ; 10: \rho_{\mathrm{rt}}=1.0 \Omega \mathrm{cm}$ and $E_{\mathrm{a}}=0.12 \mathrm{eV}$ at $\left.1.8 \mathrm{GPa}\right)$. The temperature dependencies of the magnetic susceptibilities of $\mathbf{9}$ and $\mathbf{1 0}$ were in accordance with the Curie-Wiess law. However, significantly small $\chi$ values at $300 \mathrm{~K}$ indicate diamagnetic features $\left(\chi=2.9 \times 10^{-5} \mathrm{~cm}^{3} \mathrm{~mol}^{-1}\right.$ for 9 and $\chi=2.3 \times 10^{-5} \mathrm{~cm}^{3} \mathrm{~mol}^{-1}$ for 10). These results suggest that the crystals formed spin-singlet states between the dimers through the S...S contacts to the b1 direction (Table 8), which is in accordance with their conducting behaviors.

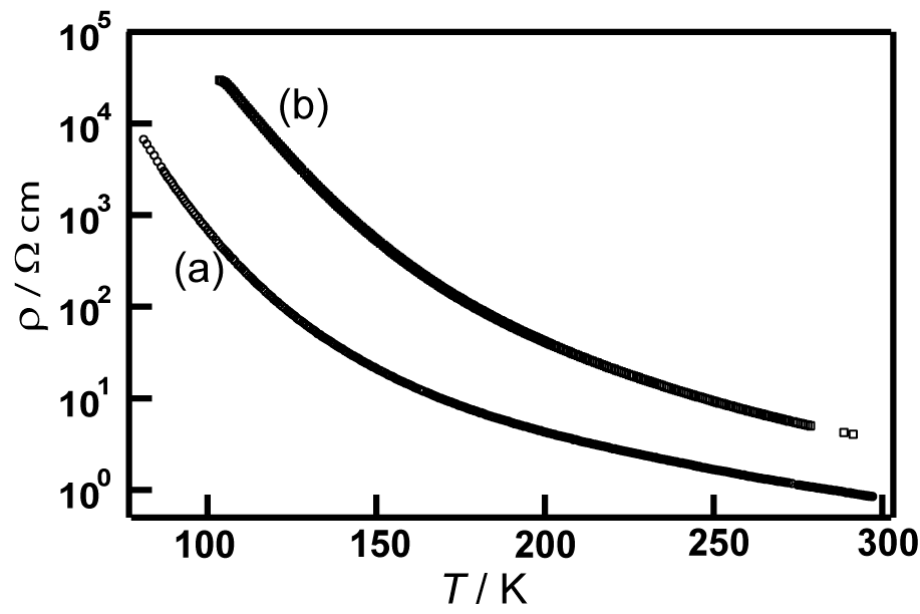

Figure 17. Temperature dependence of electrical resistivities of (a) 9 and (b) 10.

\section{Conclusions}

New donor-type nickel-dithiolene complexes based on the [Ni(dddt) $)_{2}$ skeleton fused with bulky cycloalkane substituents were synthesized as new components of molecular conductors. All the neutral crystals were crystallized in cis-[Ni(cis-Cn-dddt) 2 ] conformations with cis-oriented $(R, S)$ conformations around the cycloalkylene groups due to the $[2+$ 4] cycloadditions. The flexible cycloalkane moieties in the molecules can induce unique molecular arrangements in their neutral crystals. The three-dimensional network and onedimensional columnar structures were constructed through intermolecular $S \cdots S$ contacts in crystals 5 and 8 . No intermolecular S...S contacts were observed in 6 and 7 . However, $\left[\mathrm{Ni}\left(\mathrm{C}_{6} \text {-dddt }\right)_{2}\right]$ formed a helical molecular arrangement in the crystal. New cation radical crystals $\left[\mathrm{Ni}\left(\mathrm{C}_{3}-\mathrm{dddt}\right)_{2}\right]_{2}\left(\mathrm{ClO}_{4}{ }^{-}\right.$or $\left.\mathrm{PF}_{6}{ }^{-}\right)$with dimerized structures were successfully obtained by electrochemical crystallization, which formed different electronic structures of the $\left[\mathrm{Ni}(\mathrm{dddt})_{2}\right]_{3}(\mathrm{X})_{2}$ crystals [55,57,99-103]. The radical cation crystals were insulators due to the spin-singlet states between the dimers through the strong intermolecular S …S contacts. However, the donors with cycloalkane substituents can adjust the proportions of the inter- and intra-dimer interactions through the S...S contacts in their radical cation crystals by modification of the cycloalkane moieties, and allow for the realization of various cation radical crystals with unique donor arrangements by introducing linear, tetrahedral, and octahedral anions. Moreover, neutral crystals are potential candidates for new single-component molecular conductors [58-63].

Supplementary Materials: The following are available online at https:/ /www.mdpi.com/article/10 $.3390 /$ cryst11101154/s1, Figure S1: Molecular structure of $\mathbf{1 0}$ along vertical and parallel directions on the molecular plane with atom labels. Figure S2: Crystal structure of $\mathbf{1 0}$ along the (a) $a$, (b) $b$, and (c) $c$ axes. Hydrogen atoms are omitted for clarity. The dashed lines indicate sulfur-sulfur distances shorter than the sum of the van der Waals radius ( $<3.70 \AA$ ), CIFs: CCDC numbers 2103657-2103665 for $5-8,9$, and 10 . 
Author Contributions: Conceptualization, project administration, writing-original draft preparation, writing-review and editing, and funding acquisition, K.K.; investigation and data curation, M.S., S.A., N.H., and T.K.; supervision, T.A., R.K., and J.-i.Y. All authors have read and agreed to the published version of the manuscript.

Funding: This research was funded by a Grant-in-Aid for Scientific Research (B) [grant number JP18H01956]; and the Research Program of the Dynamic Alliance for Open Innovation Bridging Human, Environment and Materials of the Network Joint Research Center for Materials and Devices [grant number 20214021].

Institutional Review Board Statement: Not applicable.

Informed Consent Statement: Not applicable.

Acknowledgments: We thank Takeo Fukunaga from RIKEN and Yoshitaka Kawasugi from Toho University for technical support related to the X-ray crystallographic analyses and the resistivity measurements under hydrostatic pressures.

Conflicts of Interest: The authors declare no conflict of interest.

\section{References}

1. Narita, M.; Pittman, C.U., Jr. Preparation of tetrathiafulvalenes (TTF) and their selenium analogs -Tetraselenafulvalenes (TSeF). Synthesis 1976, 489-514. [CrossRef]

2. Kistenmacher, T.J.; Phillips, T.E.; Cowan, D.O. The crystal structure of the 1:1 radical cation-radical anion salt of 2,2'-bis-1,3-dithiole (TTF) and 7,7,8,8-tetracyanoquinodimethane (TCNQ). Acta Cryst. 1974, B30, 763-768. [CrossRef]

3. Coleman, L.B.; Cohen, M.J.; Sandman, D.J.; Yamagishi, F.G.; Garito, A.F.; Heeger, A.J. Superconducting fluctuations and the peierls instability in an organic solid. Solid State Commun. 1973, 12, 1125-1132. [CrossRef]

4. Ferraris, J.; Cowan, D.O.; Walatka, V.; Perlstein, J.H. Electron transfer in a new highly conducting donor-acceptor complex. J. Am. Chem. Soc. 1973, 95, 948-949. [CrossRef]

5. Jerome, D.; Mazaud, A.; Ribault, M.; Bechgaard, K. Superconductivity in a synthetic organic conductor (TMTSF) ${ }_{2} \mathrm{PF}_{6}$. J. Phys. Lett. 1980, 41, L95. [CrossRef]

6. Williams, J.M.; Ferraro, J.R.; Thorn, R.J.; Carlson, K.D.; Geiser, U.; Wang, H.H.; Kini, A.M.; Whangbo, M.-H. Organic Superconductors (Including Fullerenes); Prentice Hall: Englewood Cliffs, NJ, USA, 1992. [CrossRef]

7. Ishiguro, T.; Yamaji, K.; Saito, G. Organic Superconductors, 2nd ed.; Springer Ser. Solid-State Sci.; Springer: Berlin, Germany, 1998; Volume 18

8. Fabre, J.M. From the organic molecule to superconductors. J. Phys. IV 2000, 10, Pr3-19-Pr3-33. [CrossRef]

9. Bechgaard, K.; Jacobsen, C.S.; Mortensen, V.; Thorup, N. The properties of five highly conducting salts: $(\mathrm{TMTSF})_{2} \mathrm{X}, \mathrm{X}=$ $\mathrm{PF}_{6}{ }^{-}, \mathrm{AsF}_{6}{ }^{-}, \mathrm{SbF}_{6}{ }^{-}, \mathrm{BF}_{4}{ }^{-}$and $\mathrm{NO}_{3}{ }^{-}$, derived from tetramethyltetraselenafulvalene (TMTSF). J. Solid State Commun. 1980, 33, 1119-1125. [CrossRef]

10. Urayama, H.; Yamochi, H.; Saito, G.; Nozawa, K.; Sugano, T.; Kinoshita, M.; Sato, S.; Oshima, K.; Kawamoto, A.; Tanaka, J. A New ambient pressure organic superconductor based on BEDT-TTF with Tc higher than $10 \mathrm{~K}\left(T_{\mathrm{c}}=10.4 \mathrm{~K}\right)$. Chem. Lett. 1988, 55-58. [CrossRef]

11. Williams, J.M.; Kini, A.M.; Wang, H.H.; Carlson, K.D.; Geiser, U.; Montgomery, L.K.; Pyrka, G.J.; Watkins, D.M.; Kommers, J.K.; Boryschuk, S.J.; et al. Semiconductor-semiconductor transition $(42 \mathrm{~K})$ to the highest-Tc organic superconductor, $x-(\mathrm{ET})_{2} \mathrm{Cu}\left[\mathrm{N}(\mathrm{CN})_{2}\right] \mathrm{Cl}$ $\left(T_{\mathrm{C}}=12.5 \mathrm{~K}\right)$. Inorg. Chem. 1990, 29, 3272-3274. [CrossRef]

12. Papavassiliou, G.C.; Mousdis, G.A.; Zambounis, J.S.; Terzis, A.; Hountas, A.; Hilti, B.; Mayer, C.W.; Pfeiffer, J. Low temperature measurements of the electrical conductivities of some charge transfer salts with the asymmetric donors MDT-TTF, EDT-TTF and EDT-DSDTF. (MDT-TTF $)_{2} \mathrm{AuI}_{2}$, a new superconductor $\left(T_{\mathrm{c}}=3.5 \mathrm{~K}\right.$ at ambient pressure). Synth. Met. 1988, 27 , B379-B383. [CrossRef]

13. Kikuchi, K.; Murata, K.; Honda, Y.; Namiki, T.; Saito, K.; Ishiguro, T.; Kobayashi, K.; Ikemoto, I. On ambient-pressure superconductivity in organic conductors: Electrical properties of $(\mathrm{DMET})_{2} \mathrm{I}_{3},(\mathrm{DMET})_{2} \mathrm{I}_{2} \mathrm{Br}$ and $(\mathrm{DMET})_{2} \mathrm{IBr}_{2}$. J. Phys. Soc. Jpn. 1987, 56, 3436-3439. [CrossRef]

14. Shibaeva, R.P.; Yagubskii, E.B. Molecular conductors and superconductors based on trihalides of BEDT-TTF and some of Its analogues. Chem. Rev. 2004, 104, 5347-5378. [CrossRef]

15. Geiser, U.; Schlueter, J.A. Conducting organic radical cation salts with organic and organometallic anions. Chem. Rev. 2004, 104, 5203-5242. [CrossRef]

16. Kobayashi, H.; Cui, H.-B.; Kobayashi, A. Organic metals and superconductors based on BETS (BETS = Bis(ethylenedithio) tetraselenafulvalene). Chem. Rev. 2004, 104, 5265-5288. [CrossRef] [PubMed]

17. Uji, S.; Shinagawa, H.; Terashima, T.; Yakabe, T.; Terai, Y.; Tokumoto, M.; Kobayashi, A.; Tanaka, H.; Kobayashi, H. MagneticField-induced superconductivity in a two-dimensional organic conductor. Nature 2001, 410, 908-910. [CrossRef] 
18. Kobayashi, H.; Tomita, H.; Naito, T.; Kobayashi, A.; Sakai, F.; Watanabe, T.; Cassoux, P. New BETS Conductors with Magnetic Anions (BETS) bis(ethylenedithio)tetraselenafulvalene). J. Am. Chem. Soc. 1996, 118, 368-377. [CrossRef]

19. Aoyagi, I.; Katsuhara, M.; Mori, T. Syntheses and structures of highly soluble bis(ethylenedithio)tetrathiafulvalene molecules with alkyl chains. Sci. Tech. Adv. Mater. 2004, 5, 443-447. [CrossRef]

20. Matsumiya, S.; Izuoka, A.; Sugawara, T.; Taruishi, T.; Kawada, Y. Effect of methyl substitution on conformation and molecular arrangement of BEDT-TTF derivatives in the crystalline environment. Bull. Chem. Soc. Jpn. 1993, 66, 513-522. [CrossRef]

21. Riobé, F.; Avarvari, N. Electroactive oxazoline ligands. Coord. Chem. Rev. 2010, 254, 1523-1533. [CrossRef]

22. Awheda, I.; Krivickas, J.; Yang, S.; Martin, L.; Guziak, M.A.; Brooks, A.C.; Pelletier, F.; Le Kerneau, M.; Day, P.; Horton, P.N.; et al. Synthesis of new chiral organosulfur donors with hydrogen bonding functionality and their first charge transfer salts. Tetrahedron 2013, 69, 8738-8750. [CrossRef]

23. Biet, T.; Fihey, A.; Cauchy, T.; Vanthuyne, N.; Roussel, C.; Crassous, J.; Avarvar, N. Ethylenedithio-tetrathiafulvalene-helicenes: Electroactive helical precursors with switchable chiroptical properties. Chem. A Eur. J. 2013, 19, 13160-13167. [CrossRef]

24. Yang, S.; Pop, F.; Melan, C.; Brooks, A.C.; Martin, L.; Horton, P.; Auban-Senzier, P.; Rikken, G.L.J.A.; Avarvari, N.; Wallis, J.D. Charge transfer complexes and radical cation salts of chiral methylated organosulfur donors. CrystEngComm 2014, 16, 3906-3916. [CrossRef]

25. Chas, M.; Lemarié, M.; Guleab, M.; Avarvari, N. Chemo- and enantioselective sulfoxidation of bis(ethylenedithio)tetrathiafulvalene (BEDT-TTF) into chiral BEDT-TTF-sulfoxide. Chem. Commun. 2008, 220-222. [CrossRef]

26. Chas, M.; Riobé, F.; Sancho, R.; Minguíllon, C.; Avarvari, N. Selective monosulfoxidation of tetrathiafulvalenes into chiral TTF-sulfoxides. Chirality 2009, 21, 818-825. [CrossRef]

27. Karrer, A.; Wallis, J.D.; Dunitz, J.D.; Hilti, B.; Mayer, C.W.; Biirkle, M.; Pfeiffer, J. Structures and electrical properties of some new organic conductors derived from the donor molecule TMET (S,S,S,S-Bis(dimethylethylenedithio)tetrathiafulvalene). Helv. Chim. Acta 1987, 70, 942-953. [CrossRef]

28. Krivickas, S.J.; Ichikawa, A.; Takahashi, K.; Tajima, H.; Wallis, J.D.; Mori, H. One-dimensional antiferromagnetic behavior of a chiral molecular crystal, $\alpha^{\prime}-(S, S-D M B E D T-T T F){ }_{2} \mathrm{PF}_{6}$. Synth. Met. 2011, 161, 1563-1565. [CrossRef]

29. Krivickas, S.J.; Hashimoto, C.; Yoshida, J.; Ueda, A.; Takahashi, K.; Wallis, J.D.; Mori, H. Synthesis of racemic and chiral BEDT-TTF derivatives possessing hydroxy groups and their achiral and chiral charge transfer complexes. Beilstein J. Org. Chem. 2015, 11, 1561-1569. [CrossRef]

30. Madalan, A.M.; Réthoré, C.; Fourmigué, M.; Canadell, E.; Lopes, E.B.; Almeida, M.; Auban-Senzier, P.; Avarvari, N. Order versus disorder in chiral tetrathiafulvalene-oxazoline radical-cation salts: Structural and theoretical investigations and physical properties. Chem. Eur. J. 2010, 16, 528-537. [CrossRef]

31. Matsumiya, S.; Izuoka, A.; Sugawara, T.; Taruishi, T.; Kawada, Y.; Tokumoto, M. Crystal ctructure and conductivity of chiral radical ion salts $\left(\mathrm{Me}_{2} \mathrm{ET}\right)_{2} \mathrm{X}$. Bull. Chem. Soc. Jpn. 1993, 66, 1949-1954. [CrossRef]

32. Réthoré, C.; Avarvari, N.; Canadell, E.; Auban-Senzier, P.; Fourmigué, M. Chiral molecular metals: Syntheses, structures, and properties of the $\mathrm{AsF}_{6}$-salts of racemic $( \pm)-,(\mathrm{R})-$, and $(\mathrm{S})$-tetrathiafulvalene-oxazoline derivatives. J. Am. Chem. Soc. 2005, 127, 5748-5749. [CrossRef] [PubMed]

33. Pop, F.; Allain, M.; Auban-Senzier, P.; Martínez-Lillo, J.; Lloret, F.; Julve, M.; Canadell, E.; Avarvari, N. Enantiopure conducting salts of dimethylbis(ethylenedithio)tetrathiafulvalene (DM-BEDT-TTF) with the hexachlororhenate(IV) anion. Eur. J. Inorg. Chem. 2014, 24, 3855-3862. [CrossRef]

34. Avarvari, N.; Wallis, J.D. Strategies towards chiral molecular conductors. J. Mater. Chem. 2009, 19, 4061-4076. [CrossRef]

35. Zambounis, J.S.; Muyer, C.W.; Huuenstein, K.; Hilti, B.; HoJherr, W.; Pfegfer, J.; Biirkle, M.; Rihs, G. Crystal structure and electrical properties of $\kappa-((S, S) \text {-DMSEDT-TTF })_{2} \mathrm{ClO}_{4}$. Adv. Mater. 1992, 4, 33-35. [CrossRef]

36. Yang, S.; Brooks, A.C.; Martin, L.; Day, P.; Li, H.; Horton, P.; Malec, L.; Wallis, J.D. Novel enantiopure bis(pyrrolo)tetrathiafulvalene donors exhibiting chiral crystal packing arrangements. CrystEngComm 2009, 11, 993-996. [CrossRef]

37. Wallis, J.D.; Karrer, A.; Dunitz, J.D. Chiral metals? A chiral substrate for organic conductors and superconductors. Helv. Chim. Acta 1986, 69, 69-70. [CrossRef]

38. Short, J.I.; Blundell, T.J.; Krivickas, S.J.; Yang, S.; Wallis, J.D.; Akutsu, H.; Nakazawa, Y.; Martin, L. Chiral molecular conductor with an insulator-metal transition close to room temperature. Chem. Commun. 2020, 56, 9497-9500. [CrossRef]

39. Saad, A.; Jeannin, O.; Fourmigué, M. Chiral, flexible binaphthol-substituted tetrathiafulvalenes. Tetrahedron 2011, 67, 3820-3829. [CrossRef]

40. Pop, F.; Auban-Senzier, P.; Canadell, E.; Avarvari, N. Anion size control of the packing in the metallic versus semiconducting chiral radical cation salts (DM-EDT-TTF $)_{2} \mathrm{XF}_{6}(\mathrm{X}=\mathrm{P}, \mathrm{As}, \mathrm{Sb})$. Chem. Commun. 2016, 52, 12438-12441. [CrossRef]

41. Pop, F.; Auban-Senzier, P.; Frąckowiak, A.; Ptaszyński, K.; Olejniczak, I.; Wallis, J.D.; Canadell, E.; Avarvari, N. Chirality driven metallic versus semiconducting behavior in a complete series of radical cation salts based on dimethyl-ethylenedithiotetrathiafulvalene (DM-EDT-TTF). J. Am. Chem. Soc. 2013, 135, 17176-17186. [CrossRef] [PubMed]

42. Galán-Mascarós, J.R.; Coronado, E.; Goddard, P.A.; Singleton, J.; Coldea, A.I.; Wallis, J.D.; Coles, S.J.; Alberola, A. A chiral ferromagnetic molecular metal. J. Am. Chem. Soc. 2010, 132, 9271-9273. [CrossRef] [PubMed]

43. Kimura, S.; Maejima, T.; Suzuki, H.; Chiba, R.; Mori, H.; Kawamoto, T.; Mori, T.; Moriyama, H.; Nishio, Y.; Kajita, K. A new organic superconductor $\beta$-(meso-DMBEDT-TTF) ${ }_{2} \mathrm{PF}_{6}$. Chem. Commun. 2004, 2454-2455. [CrossRef] 
44. Kimura, S.; Suzuki, H.; Maejima, T.; Mori, H.; Yamaura, J.; Kakiuchi, T.; Sawa, H.; Moriyama, H. Checkerboard-type chargeordered state of a pressure-induced superconductor, $\beta$-(meso-DMBEDT-TTF) ${ }_{2} \mathrm{PF}_{6}$. J. Am. Chem. Soc. 2006, 128, $1456-1457$. [CrossRef] [PubMed]

45. Suzuki, H.; Yamashita, K.; Suto, M.; Maejima, T.; Kimura, S.; Mori, H.; Nishio, Y.; Kajita, K.; Moriyama, H. Control of electronic state in the 2D hydrogen-bonded system: $\beta^{\prime \prime}-($ CnDT-EDO-TTF)2(PF6)x $(n=5,6,7,8)$. Synth. Met. 2004, 144, 89-95. [CrossRef]

46. Kimura, S.; Suzuki, H.; Maejima, T.; Suto, M.; Yamashita, K.; Ichikawa, S.; Mori, H.; Moriyama, H.; Mochida, T.; Nishio, Y.; et al. Crystal structures and electrical conductivities controlled by CH/n interactions. J. Phys. IV 2004, 114, 521-522. [CrossRef]

47. Kato, R. Conducting metal dithiolene complexes: Structural and electronic properties. Chem. Rev. 2004, 104, 5319-5346. [CrossRef]

48. Kobayashi, A.; Fujiwara, E.; Kobayashi, H. Single-component molecular metals with extended-TTF Dithiolate ligands. Chem. Rev. 2004, 104, 5243-5264. [CrossRef] [PubMed]

49. Tanaka, H.; Okano, Y.; Kobayashi, H.; Suzuki, W.; Kobayashi, A. A three-dimensional synthetic metallic crystal composed of single-component molecules. Science 2001, 291, 285-287. [CrossRef] [PubMed]

50. Ni, J.M.; Pan, B.L.; Song, B.Q.; Huang, Y.Y.; Zeng, J.Y.; Yu, Y.J.; Cheng, E.J.; Wang, L.S.; Dai, D.Z.; Kato, R.; et al. Absence of magnetic thermal conductivity in the quantum spin liquid candidate $\mathrm{EtMe}_{3} \mathrm{Sb}\left[\mathrm{Pd}(\mathrm{dmit})_{2}\right]_{2}$. Phys. Rev. Lett. 2019, 123, 247204. [CrossRef]

51. Bourgeois-Hope, P.; Laliberté, F.; Lefrançois, E.; Grissonnanche, G.; de Cotret, S.R.; Gordon, R.; Kitou, S.; Sawa, H.; Cui, H.; Kato, R.; et al. Thermal conductivity of the quantum spin liquid candidate $\mathrm{EtMe}_{3} \mathrm{Sb}\left[\mathrm{Pd}(\mathrm{dmit})_{2}\right]_{2}$ : No evidence of mobile gapless excitations. Phys. Rev. X 2019, 9, 041051. [CrossRef]

52. Itou, T.; Watanabe, E.; Maegawa, S.; Tajima, A.; Tajima, N.; Kubo, K.; Kato, R.; Kanoda, K. Slow dynamics of electrons at a metal-Mott insulator boundary in an organic system with disorder. Sci. Adv. 2017, 3, e1601594. [CrossRef] [PubMed]

53. Miyagawa, K.; Kanoda, K. NMR studies on two-dimensional molecular conductors and superconductors: Mott transition in к-(BEDT-TTF) ${ }_{2}$ X. Chem. Rev. 2004, 104, 5635-5653. [CrossRef]

54. Kato, R.; Cui, H.B.; Tsumuraya, T.; Miyazaki, T.; Suzumura, Y. Emergence of the Dirac electron system in a single-component molecular conductor under high pressure. J. Am. Chem. Soc. 2017, 139, 1770-1773. [CrossRef] [PubMed]

55. Wang, H.H.; Fox, S.B.; Yagubskii, E.B.; Kushch, L.A.; Kotov, A.I.; Whangbo, M.-H. Direct observation of the electron-donating property of the 5,6-dihydro-1,4-dithiin-2,3-dithiolate (dddt) ligands in square planar $\mathrm{M}(\mathrm{dddt})_{2}$ complexes $(\mathrm{M}=\mathrm{Ni}, \mathrm{Pd}, \mathrm{Pt}$, and Au). J. Am. Chem. Soc. 1997, 119, 7601-7602. [CrossRef]

56. Cui, H.; Tsumuraya, T.; Yeung, H.H.-M.; Coates, C.S.; Warren, M.R.; Kato, R. High Pressure Crystal Structure and Electrical Properties of a Single Component Molecular Crystal [Ni(dddt) 2 ( dddt = 5,6-dihydro-1,4-dithiin-2,3-dithiolate). Molecules 2019, 24, 1843. [CrossRef] [PubMed]

57. Kushch, L.A.; Gritsenko, V.V.; Buravov, L.I.; Khomenko, A.G.; Shilov, G.V.; Dyachenko, O.A.; Merzhanov, V.A.; Yagubskii, E.B.; Rousseau, R.; Canadell, E. The M(dddt $)_{2}$ family of conducting complexes: [Ni(dddt $\left.)_{2}\right]_{3}\left(\mathrm{AuBr}_{2}\right)_{2}$, the first quasi-two-dimensional metal stable down to at least 1.3 K. J. Mater. Chem. 1995, 5, 1633-1638. [CrossRef]

58. Tsumuraya, T.; Kato, R.; Suzumura, Y. Effective Hamiltonian of topological nodal line semimetal in single-component molecular conductor $\left[\mathrm{Pd}(\mathrm{dddt})_{2}\right.$ ] from first-principles. J. Phys. Soc. Jpn. 2018, 87, 113701-1-113701-5. [CrossRef]

59. Kato, R.; Suzumura, Y. Novel Dirac electron in single-component molecular conductor $\left[\mathrm{Pd}(\mathrm{dddt})_{2}\right](\mathrm{dddt}=5,6$-dihydro-1,4dithiin-2,3-dithiolate). J. Phys. Soc. Jpn. 2017, 86, 064705. [CrossRef]

60. Suzumura, Y.; Cui, H.B.; Kato, R. Conductivity and resistivity of Dirac electrons in single-component molecular conductor [Pd(dddt) $)_{2}$. J. Phys. Soc. Jpn. 2018, 87, 084702. [CrossRef]

61. Liu, Z.; Wang, H.; Wang, Z.F.; Yang, J.; Liu, F. Pressure-induced organic topological nodal-line semimetal in the three-dimensional molecular crystal Pd(dddt) $)_{2}$. Phys. Rev. B 2018, 97, 155138. [CrossRef]

62. Suzumura, Y.; Tsumuraya, T.; Kato, R.; Matsuura, H.; Ogata, M. Role of Velocity Field and Principal Axis of Tilted Dirac Cones in Effective Hamiltonian of Non-Coplanar Nodal Loop. J. Phys. Soc. Jpn. 2019, 88, 124704. [CrossRef]

63. Suzumura, Y.; Kato, R.; Ogata, M. Electric transport of nodal line semimetals in single-component molecular conductors. Crystals 2020, 10, 862. [CrossRef]

64. Kato, R.; Kashimura, Y.; Sawa, H.; Okano, Y. Synthesis, structure, and electrochemical properties of new "unsymmetrical" metal dithiolate complexes. Chem. Lett. 1997, 26, 921-922. [CrossRef]

65. Kashimura, Y.; Okano, Y.; Yamaura, J.; Kato, R. Synthesis, structures, and physical properties of molecular conductors based on unsymmetrical metal-dithiolene complexes. Synth. Met. 1999, 103, 2123-2124. [CrossRef]

66. Kini, A.M.; Geiser, U.; Wang, H.-H.; Lykke, K.R.; Williams, J.M.; Campana, C.F. Alternative synthesis of (z),(z)-4,5;4',5'-bis(1,4dioxanediyl-2,3-dithio)tetrathiafulvalene (cis,cis-BDDT-TTF), and preparation, epr properties and structure of the radical cation salt (cis,cis-BDDT-TTF) ${ }_{2} \mathrm{I}_{3}$. J. Mater. Chem. 1995, 5, 1647-1652. [CrossRef]

67. Kotov, A.I.; Buravov, L.I.; Konovalikhin, S.V.; Dyachenko, O.A.; Yagubskii, E.B.; Malfant, I.; Courcet, T.; Cassoux, P.; Akimoto, J.; Honda, K.; et al. BEDT-TTF Derivatives with one and two dioxane rings and their conductive salts. Synth. Met. 1999, 102, 1630-1631. [CrossRef]

68. Nishikawa, H.; Morimoto, T.; Kodama, T.; Ikemoto, I.; Kikuchi, K.; Yamada, J.; Yoshino, H.; Murata, K. New organic superconductors consisting of an unprecedented $\pi$-electron donor. J. Am. Chem. Soc. 2002, 124, 730-731. [CrossRef] [PubMed]

69. Nishikawa, H.; Sato, Y.; Kikuchi, K.; Kodama, T.; Ikemoto, I.; Yamada, J.; Oshio, H.; Kondo, R.; Kagoshima, S. Charge ordering and pressure-induced superconductivity in $\beta^{\prime \prime}-(\mathrm{DODHT})_{2} \mathrm{PF}_{6}$. Phys. Rev. B 2005, 72, 052510-1-052510-4. [CrossRef] 
70. Svenstrup, N.; Becher, J. The organic chemistry of 1,3-Dithiole-2-thione-4,5-dithiolate (DMIT). Synthesis 1995, 215-235. [CrossRef]

71. Walker, I.R. Nonmagnetic piston-cylinder pressure cell for use at 35 kbar and above. Rev. Sci. Instrum. 1999, 70, $3402-3412$. [CrossRef]

72. Ishii, Y.; Tamura, M.; Kato, R.; Hedo, M.; Uwatoko, Y.; Môri, N. Effect of hydrostatic pressure on molecular conductors, Pd(dmit) 2 salts. Synth. Met. 2005, 152, 389-392. [CrossRef]

73. Albright, T.A.; Hoffmann, P.; Hoffmann, R. Conformational preferences and rotational barriers in polyene-ML3 transition metal complexes. J. Am. Chem. Soc. 1977, 99, 7546-7557. [CrossRef]

74. Chen, M.M.L.; Hoffmann, R. Sulfuranes. Theoretical aspects of bonding, substituent site preferences, and geometrical distortions. J. Am. Chem. Soc. 1976, 98, 1647-1653. [CrossRef]

75. Komiya, S.; Albright, T.A.; Hoffmann, R. Reductive elimination and isomerization of organogold complexes. Theoretical studies of trialkylgold species as reactive intermediates. J. Am. Chem. Soc. 1976, 98, 7255-7265. [CrossRef]

76. Rigaku Oxford Diffraction. CrysAlisPro Software system, version 1.171.40.67a; Rigaku Corporation: Wroclaw, Poland, 2012.

77. Dolomanov, O.V.; Bourhis, L.J.; Gildea, R.J.; Howard, J.A.K.; Puschmann, H. OLEX2: A complete structure solution, refinement and analysis program. J. Appl. Cryst. 2009, 42, 339-341. [CrossRef]

78. Sheldrick, G.M. SHELXT-Integrated space-group and crystal-structure determination. Acta Cryst. 2015, C71, 3-8. [CrossRef]

79. Khodorkovsky, V.Y.; Becker, J.Y.; Bernstein, J. [2 + 4] Cycloaddition to tetrathiafulvalene (TTF): A new route to multisulfur TTF derivatives. Synthesis 1992, 1071-1072. [CrossRef]

80. Gillman, J.; Hartke, K. Thion- und Dithioester, 40. [2 + 4]-Cycloadditionen von Tetrathiooxalsäuredimethylester an cyclisch konjugierte, mehrfach ungesättigte Verbindungen. Chem. Ber. 1986, 119, 2859-2867. [CrossRef]

81. Medne, R.S.; Katsens, Y.Y.; Kraupsha, I.L.; Neiland, O.Y. Bis(1,2-cyclopentylenedithio)- and bis(1,2-cyclohexylenedithio) tetrathiafulvalenes. Chem. Heterocycl. Compd. 1991, 27, 1053-1055. [CrossRef]

82. Kotov, A.I.; Faulmann, C.; Cassoux, P.; Yagubskii, E.B. New $\pi$-donor precursor molecule for the preparation of organic metals, 4,5;4',5'-bis(l,4-dioxanediyl-2,3-dithio)-tetrathiafulvalene: Synthesis and properties. J. Org. Chem. 1994, 59, 2626-2629. [CrossRef]

83. Bai, J.-F.; Zuo, J.-L.; Shi, F.-N.; Jin, R.; Shen, Z.; You, X.-Z. Synthesis and crystal structure of 4,5-(cis-cyclohexylenedithio)-1,3dithiole-2-one. J. Chem. Crystallogr. 1999, 29, 719-723. [CrossRef]

84. Kim, H.; Kobayashi, A.; Sasaki, Y.; Kato, R.; Kobayashi, H.; Nakamura, T.; Nogami, T.; Shirota, Y. Crystal and molecular structure of tetrabutylammonium bis(1,4-dithiin-2,3-dithiolato)nickelate(III), (Bun4N)[Ni(ddt) 2 ]. Bull. Chem. Soc. Jpn. 1988, 61, 2559-2562. [CrossRef]

85. Bigoli, F.; Deplano, P.; Devillanova, F.A.; Lippolis, V.; Lukes, P.J.; Mercuri, M.L.; Pellinghelli, M.A.; Trogu, E.F. New neutral nickel dithiolene complexes derived from 1,3-dialkylimidazolidine-2,4,5-trithione, showing remarkable near-IR absorption. J. Chem. Soc. Chem. Commun. 1995, 371-372. [CrossRef]

86. Bigoli, F.; Deplano, P.; Mercuri, M.L.; Pellinghelli, M.A.; Pintus, G.; Trogu, E.F.; Zonnedda, G.; Wang, H.H.; Williams, J.M. Novel oxidation and reduction products of the neutral nickel-dithiolene Ni(Pr2itimdt)2 (Pr2itimdt is the monoanion of 1,3diisopropylimidazolidine-2,4,5-trithione). Inorg. Chim. Acta 1998, 273, 175-183. [CrossRef]

87. Bigoli, F.; Deplano, P.; Devillanova, F.A.; Ferraro, J.R.; Lippolis, V.; Lukes, P.J.; Mercuri, M.L.; Pellinghelli, M.A.; Trogu, E.F.; Williams, J.M. Syntheses, X-ray crystal structures, and spectroscopic properties of new nickel-dithiolenes and related compounds. Inorg. Chem. 1997, 36, 1218-1226. [CrossRef] [PubMed]

88. Charlton, A.; Hill, C.A.S.; Underhill, A.E.; Malik, K.M.A.; Hursthouse, M.B.; Karaulov, A.I.; Møller, J. Synthesis, physical properties and x-ray crystal structures of a series of nickel complexes based on n-alkylthio-substituted ethylene-1,2-dithiolene ligands. J. Mater. Chem. 1994, 4, 1861-1866. [CrossRef]

89. Zuo, J.-L.; Yao, T.-M.; You, F.; You, X.-Z.; Fun, H.-K.; Yip, B.-C. Syntheses, characterization and non-linear optical properties of nickel complexes of multi-sulfur 1,2-dithioiene with strong near-IR absorption. J. Mater. Chem. 1996, 6, 1633-1637. [CrossRef]

90. Zuo, J.-L.; You, F.; You, X.-Z.; Fun, H.-K. Syntheses and properties of the neutral nickel complexes of 1,2-dithiolates MEDT and PHDT. The crystal structure of [Ni(MEDT) $)_{2}$ ]. Polyhedron 1997, 16, 1465-1469. [CrossRef]

91. Proctor, K.A.; Boyle, P.D.; Bereman, R.D. The synthesis and characterization of new neutral metal complexes containing the tetrathioethylene unit. J. Coord. Chem. 1996, 39, 43-58. [CrossRef]

92. Schultz, A.J.; Wang, H.H.; Soderholm, L.C.; Sifter, T.L.; Williams, J.M.; Bechgaard, K.; Whangbo, M.H. Crystal structures of bis(5,6-dihydro-1,4-dithiin-2,3-dithiolato)gold and tetrabutylammonium bis(5,6-dihydro-1,4-dithiin-2,3-dithiolato)nickelate(1-)

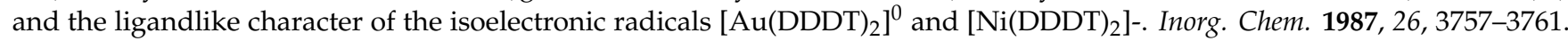
[CrossRef]

93. Ji, Y.; Zuo, J.-L.; Chen, L.; Tian, Y.-Q.; Song, Y.; Li, Y.-Z.; You, X.-Z. Synthesis, characterization and optical limiting effect of nickel complexes of multi-sulfur 1,2-dithiolene. J. Phys. Chem. Solids 2005, 66, 207-212. [CrossRef]

94. Bai, J.-F.; Zuo, J.-L.; Tan, W.-L.; Ji, W.; Shen, Z.; Fun, H.-K.; Chinnakali, K.; Razak, I.A.; You, X.-Z.; Che, C.-M. Synthesis, structure and optical limiting effect of two new nickel complexes containing strongly bound geometrically fixed multi-sulfur 1,2-dithiolene ligands showing remarkable near-IR absorption. J. Mater. Chem. 1999, 9, 2419-2423. [CrossRef]

95. Mueller-Westerhoff, U.T.; Vance, B.; Yoon, D.I. The synthesis of dithiolene dyes with strong near-IR absorption. Tetrahedron 1991, 47, 909-932. [CrossRef]

96. Herman, Z.S.; Kirchner, R.F.; Loew, G.H.; Mueller-Westerhoff, U.T.; Nazzal, A.; Zerner, M.C. Electronic spectra and structure of bis(ethylene-1,2-dithiolato)nickel and bis-(propene-3-thione-1-thiolato)nickel. Inorg. Chem. 1982, 21, 46-56. [CrossRef] 
97. Tan, W.L.; Ji, W.; Zuo, J.L.; Bai, J.F.; You, X.Z.; Lim, J.H.; Yang, S.; Hagan, D.J.; Van Stryland, E.W. Optical-limiting properties of neutral nickel-dithiolenes. Appl. Phys. B 2000, 70, 809-812. [CrossRef]

98. Lee, H.-J.; Noh, D.-Y. Electrochemistry and strong near-IR absorption of the $\left[\mathrm{Ni}(\mathrm{dphdt})_{2}\right]^{\mathrm{n}}$ complexes $(n=-1,0 ; \mathrm{dphdt}=$ 5,6-diphenyl-1,4-dithiin-2,3-dithiolate); X-ray crystal structure of $\left(\mathrm{Ph}_{4} \mathrm{P}\right)\left[\mathrm{Ni}(\mathrm{dphdt})_{2}\right]\left(\mathrm{CH}_{2} \mathrm{Cl}_{2}\right)$. Polyhedron 2000, 19, 425-429. [CrossRef]

99. Nagapetyan, S.S.; Shklover, V.E.; Struchkov, Y.T.; Kotov, A.I.; Yagubskii, E.B.; Ukhin, L.Y. Synthesis andthe X-ray study of $\left[\mathrm{Ni}(\mathrm{DDDT})_{2}\right]_{3}\left(\mathrm{ClO}_{4}\right)_{2}$. Trimeric cationic dithiolate complex-A precursor of low-dimensional metals of a new type. Dokl. Akad. Nauk SSSR 1990, 310, 94-98.

100. Yagubskii, E.B. Effect of metal (M) and counter ion nature on crystal structure and conducting properties of $\mathrm{M}(\mathrm{dddt})_{2}$ cation complexes. Synth. Met. 2003, 133-134, 385-387. [CrossRef]

101. Kotov, A.I.; Buravov, L.I.; Yagubskii, E.B.; Khasanov, S.S.; Zorina, L.V.; Shibaeva, R.P.; Canadell, E. Comparative study of BEDT-TTF and $\mathrm{Ni}(\mathrm{dddt})_{2}$ electroconducting salts with the $\mathrm{HXO}_{4}(\mathrm{X}=\mathrm{Se}, \mathrm{S})$ anions. Synth. Met. 2001, 124, 357-362. [CrossRef]

102. Yagubskii, E.B.; Kotov, A.I.; Khomenko, A.G.; Buravov, L.I.; Schegolev, A.I.; Shibaeva, R.P. $\left[\mathrm{Ni}\left(\mathrm{dddt}_{2}\right]_{3}\left(\mathrm{HSO}_{4}\right)_{2}\right.$, the first metal among the $\mathrm{M}(\mathrm{dddt})_{2}$ salts. Synth. Met. 1992, 46, 255-259. [CrossRef]

103. Yagubskii, E.B.; Kotov, A.I.; Laukhina, E.E.; Ignatiev, A.A.; Buravov, L.I.; Khomenko, A.G.; Shklover, V.E.; Nagapetyan, S.S.; Struchkov, Y.T. New class of metal BIS-dithiolene electroconducting solids: Cation complexes of metals with dddt. Synth. Met. 1991, 42, 2515-2522. [CrossRef]

104. Kubo, K.; Nakao, A.; Ishii, Y.; Yamamoto, T.; Tamura, M.; Kato, R.; Yakushi, K.; Matsubayashi, G. Electrical Properties and Electronic States of Molecular Conductors Based on Unsymmetrical Organometallic-Dithiolene Gold(III) Complexes. Inorg. Chem. 2008, 47, 5495-5502. [CrossRef] [PubMed] 